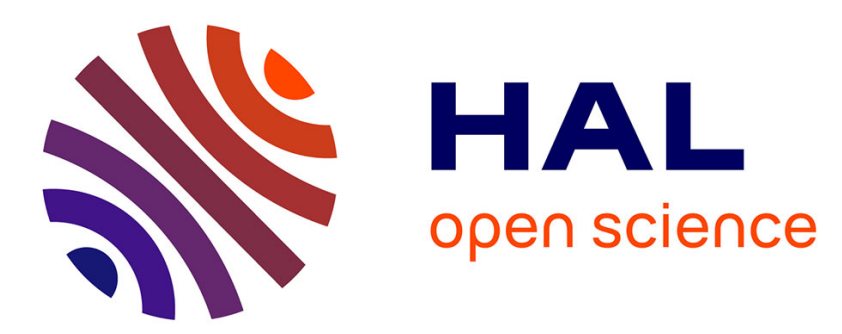

\title{
A non-parametric revealed preference test of optimal intra-firm resource allocation
}

\author{
Jonathan Stuart Seaton
}

\section{To cite this version:}

Jonathan Stuart Seaton. A non-parametric revealed preference test of optimal intra-firm resource allocation. Applied Economics, 2009, 41 (27), pp.3463-3476. 10.1080/00036840701537836 . hal00582170

\section{HAL Id: hal-00582170 \\ https://hal.science/hal-00582170}

Submitted on 1 Apr 2011

HAL is a multi-disciplinary open access archive for the deposit and dissemination of scientific research documents, whether they are published or not. The documents may come from teaching and research institutions in France or abroad, or from public or private research centers.
L'archive ouverte pluridisciplinaire HAL, est destinée au dépôt et à la diffusion de documents scientifiques de niveau recherche, publiés ou non, émanant des établissements d'enseignement et de recherche français ou étrangers, des laboratoires publics ou privés. 


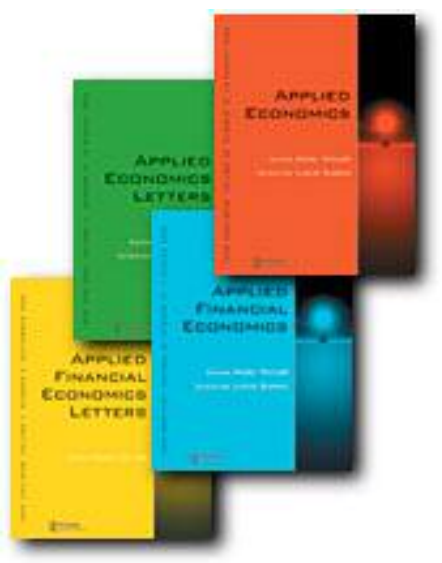

A non-parametric revealed preference test of optimal intra-firm resource allocation

\begin{tabular}{|c|c|}
\hline Journal: & Applied Economics \\
\hline Manuscript ID: & APE-06-0513.R1 \\
\hline Journal Selection: & Applied Economics \\
\hline $\begin{array}{r}\text { Date Submitted by the } \\
\text { Author: }\end{array}$ & 13-Jun-2007 \\
\hline Complete List of Authors: & Seaton, Jonathan; Loughborough University, The Business School \\
\hline JEL Code: & $\begin{array}{l}\text { C70 - General \&lt; C7 - Game Theory and Bargaining Theory \&lt; C } \\
\text { - Mathematical and Quantitative Methods, D13 - Household } \\
\text { Production and Intrahousehold Allocation \&lt; D1 - Household } \\
\text { Behavior and Family Economics \&lt; D - Microeconomics, D70 - } \\
\text { General \&lt; D7 - Analysis of Collective Decision-Making \&lt; D - } \\
\text { Microeconomics, L20 - General \&lt; L2 - Firm Objectives, } \\
\text { Organization, and Behavior \&lt; L - Industrial Organization }\end{array}$ \\
\hline Keywords: & $\begin{array}{l}\text { C70 - General \&lt; C7 - Game Theory and Bargaining Theory \&lt; C } \\
\text { - Mathematical and Quantitative Methods, D13 - Household } \\
\text { Production and Intrahousehold Allocation \&lt; D1 - Household } \\
\text { Behavior and Family Economics \&lt; D - Microeconomics, D70 - } \\
\text { General \&lt; D7 - Analysis of Collective Decision-Making \&lt; D - } \\
\text { Microeconomics, L20 - General \&lt; L2 - Firm Objectives, } \\
\text { Organization, and Behavior \&lt; L - Industrial Organization }\end{array}$ \\
\hline
\end{tabular}

\section{s) ScholarONE" \\ Manuscript Central}




\title{
A non-parametric revealed preference test of optimal intra-firm resource allocation
}

\author{
Jonathan S. Seaton \\ Business School, \\ Loughborough University, \\ Loughborough, \\ Leicestershire LE11 3TU, \\ $U K$
}

Tel: +44 (0)1509 228838

Email: J.S.Seaton@Lboro.ac.uk

22 August, 2006

\begin{abstract}
The collective rationality hypothesis initiated by Chiappori (1988) and applied by Seaton $(1997,2001)$ for a two-person household is used to distinguish the organizational behaviour of firms. Firms produce satisfaction to groups as traditional managerial and early behavioural theories of the firm of Williamson, Baumol and Marris suggest, as well as more modern principle-agent models. Intra firm bargaining leads to a Pareto optimal outcome. What makes this work an important contribution is that it identifies a set of non-vacuous testable restrictions to empirically detect if firm level data satisfy Pareto optimal behaviour for the main decision makers in the organization.
\end{abstract}




\section{Introduction}

In this paper the relationship between a two-person/group organisation is introduced using traditional game theory models. Secondly, a set of non-vacuous conditions for the outcome to be compatible with any bargaining/cooperative solution ((Nash 1950, 1951), Kalai-Smorodinsky (1975), Rubinstein (1982)), is determined. That data may disagree with these restrictions will imply that the firm is internally managed noncooperatively or inefficiently relative to the objectives set by the players. The methodology is derived directly from the theoretical work of Chiappori (1988a) and empirical implementation by Seaton $(1997,2001)$. This technique has advantages over traditional methods of measuring firm level efficiency which implicitly assume that firm level agents share an identical objective function.

Emphasis is made in the literature for firm behaviour to be consistent with the pursuit of pure profit maximization, see Romer (2006), revenue maximization or cost minimization, Varian (1982), when in reality firms may pursue combinations of these plus other objectives, agency, personal or even social. Our procedure does not make any of these specific assumptions except that the objective function for the firm should be concave and increasing (a production function for example, but could also represent a utility award to managers/directors or workers, see Varian (1999), p 130) and that the function can be considered as the outcome of a bargaining procedure. This is encouraging as in this sense it allows a wider class of firm level efficiency than traditional methods. Another important contribution is that the methodology can take into account the transitivity property of players' preferences, which allows analysis of inconsistency with both the strong axiom of revealed preference (SARP) 
and the general axiom of revealed preference (GARP), which is traditionally thought of as a highly intractable problem for most data sets, Varian (2006), Famulari (1995).

In what follows our analysis will first identify the revealed preference problem of aggregation that lies at the heart of the issue (see Varian (1983) p. 107 and Varian (1984) pp 589-590). A general discussion provides a link, see Chiappori (1988b), between this approach and game theory solutions put forward by Nash and others. We later formalise the model and distinguish the restrictions that data must obey in order for consistency with Pareto efficient behaviour. The paper is concluded with examples taken from firm level data in order to illustrate the ease of use of such a procedure.

\section{Modelling Intra-firm Resource Allocation}

\section{Firm level objectives}

What are the objectives of the firm? Does the firm act as a unit aiming for maximal profits with known costs and production function? Do managers/directors pursue their own goals given some pressure from shareholders and employees? This topic has not only concerned the pure economics, organisational behaviour and the managerial economics literature but is also a solid topic for debate in undergraduate economics principles. Recently Romer's (2006) finds that in the National Football League there is a departure from behaviour that would maximize the chance of winning and thus suggests other factors must be creeping in to objective functions such as complexity (agency issues) or information (use of experience rather than objective analysis).

In reality the firm like the household is an organisation made up of decision makers, internal and external (shareholders), who all benefit from the functioning of the organisation but do not necessarily possess common objectives, the now familiar principle-agent model, Antle and Fellingham (1990), Fama (1980), Magee (1988)) 
makes this a key issue. Following the collective household labour supply literature ${ }^{1}$ the objectives of the aggregate organisation are assumed dependent on the key decision makers. They are defined to hold objectives on firm level inputs $Z=\left(z_{A}, z_{B}\right.$, $z_{C}$ ), but we do not specify the individual objectives explicitly, neither do we need to specify who the individuals or groups are, though in many cases this should be obvious from the nature of an investigation, in partnerships for example. Indeed the only restriction is that the individuals' $(i=A, B)$ objective functions $Y_{i}\left(z_{A}, z_{B}, z_{C}\right)$, are concave and increasing in $z_{A}, z_{B}, z_{C}$.

Difference of opinion between players is inherent in this organisation and the model does not moralise on the crude efficiency of the inputs to a specific measurable output, as it is often very hard to correctly distinguish the output from the firm i.e. as quality of product, gains in social welfare of the community. It is, however, necessary for us to address the form of player interaction in a very general manner. This does not imply a schizophrenic production function, but rather the complex interplay of groups or individuals' objectives on the final aims of the firm. In essence a welfare function is discussed which is additively separable for each player's objectives.

\section{Disaggregated models of intra-firm choice and rationality}

To set the scene three forms of behaviour for an organization $R$, are reviewed, differentiated by the form of their decision-making process and control over funding by two individuals or groups $A$ and $B$. The first scenario introduces basic ideas of revealed preference whilst the second indicates the problem of aggregation. Our third

\footnotetext{
${ }^{1}$ See for example Leuthold (1968), Manser and Brown (1980), McElroy and Horney (1981), Lundberg (1988), Bourguinon and Chiappori (1992), Famulari (1995), Fortin and Lacroix (1997), Browning and Chiappori (1998), Vermeulen (2002).
} 
and final case examines two-player behaviour for the organisation and highlights the problem of organisational efficiency given individual/group objectives.

Common funding, common objectives

The central concept of revealed preference is fairly straightforward (see Varian (1999, 2006)). Consider figure 1 , a firm, $A$, with only two inputs $z_{1}$ and $z_{2}$, makes a choice of input mix $A_{l}$, from the set of input mixes, on or below the current expenditure constraint $E_{1}$, like bundle $A_{3}$. Now consider a change in input prices, $z_{1}$ becomes more expensive and $z_{2}$ cheaper. Faced by a new a new expenditure constraint $E_{2}$ the firm chooses $A_{2}$, which appears to be an entirely rational choice. However if $A$ had chosen bundle $A_{3}$ rather than $A_{2}$ then it would not be a consistent choice as the firm had already revealed a preference for $A_{1}$ over $A_{3}$.

\section{Individual funding, individual objectives}

Let us expand the discussion to two managers $i=A, B$, now in different branches who are allowed by the organisation $(R)$ to control their branch resources.

In figure $1 E_{l}$ represents the initial expenditure possibilities for each of the two agents. Players $A$ and $B$ choose affordable input bundles at points $A_{l}$ and $B_{1}$ respectively. The sum of these two inputs is represented on the total expenditure constraint $T E_{l}$ at point $R_{l}$. Given the price change we saw in the previous case for player $A$, the new choices of input mix for $A$ and $B$ on the constraint $E_{2}$, are $A_{2}$ and $B_{2}$ which total to $R_{2}$ on the new total expenditure constraint, $T E_{2}$, facing the organisation. Player $A$ 's choices are consistent as before and likewise for player $B$. However, 
looking at the overall organisational choices, these look completely irrational as $R_{l}$ was initially chosen in preference to $R_{2}$ when both were available, but upon price change, $R_{2}$ was chosen in preference to $R_{1}$ again when both were available. Thus a Neoclassical single objective function analysis of $R$ would suggest inconsistency with rational behaviour. Given the objectives of the individuals in the firms, they have made entirely consistent decisions based on their different preferences, clearly a wider set of possibilities should be allowed for the firm for aggregation of differing individual or group choices.

[Figure 1 about here]

\section{Common funding, individual objectives.}

Our analysis now moves on to show that even with a common pool of expenditure the bargaining solution yields a wider variation of behaviour than that based on a Neoclassical common objective function.

[Figure 2 about here]

Quadrant (I) of figure 2 is a familiar derivation of the Cournot game solution (C). The figure plots the dictatorship or bliss points, $\left(D_{A}, D_{B}\right)$ for players $A$ and $B$ respectively where one player has controlling choice of resource allocation of three inputs $r_{A}, r_{B}, r_{C}$. Note only two inputs need be plotted $\left(r_{A}, r_{B}\right)$ as the third is determined by the level of finance and the expenditure on the other two inputs. The isoquants representing the decreasing levels of $Y$ created for each individual, fan outwards from these bliss points, for $A, Y_{A 1}, Y_{A 2}, Y_{A C}, Y_{A 3}$, and for $\mathrm{B}, Y_{B 1}, Y_{B 2}, Y_{B C}$, $Y_{B 3}$. Reaction functions are drawn where the isoquant of one player is tangential to 
choices made for $z$ by the other. The Cournot-Nash equilibrium occurs where the two reaction curves cross. The level of $Y$ for the Cournot outcome is inferior to the bargaining outcome, which might occur anywhere along the line $a b$, where player isoquants are tangential to each other, indicating that joint production of $Y$ is maximized in the Pareto sense.

We can derive a similar diagram but measured in terms of the output vectors $Y_{A}, Y_{B}$ rather than inputs $z_{A}, z_{B}$. The transformation is performed through curves in quadrants (II) and (III) for $A$ and $B$ respectively. In quadrant (II) the level of $Y$ is determined from the contract curve and plotted against $z_{A}$ input. By definition the highest value of $Y$ possible is $Y_{A D}$ at point $D_{A}$ compared to the low value for player $A$ when point $D_{B}$, player $B$ 's bliss point, is reached from input pair $z_{A D B}, z_{B D B}$. Player $A$ would have to input $z_{A C}$ of $z$ along the contract curve, at point $b$, to generate the same level of output $Y_{A C}$ at the Cournot equilibrium (as the same isoquant $Y_{A D}$ passes through both points). The same mapping of $z$ against $Y_{A B}$ is given in quadrant (III).

If we map the results from quadrants (II) and (III) to (IV) then another familiar diagram is produced. This shows the maximal output for both players as well as the Pareto inefficient Cournot-Nash equilibrium, $C$. Points $a b$ represent the bargaining set in the sense that they signify gains to both players from cooperation and hence a motivation for optimal behaviour. The Pareto optimal solution to the bargaining outcome might come from the Nash's $(1950,1953)$ axiomatic approach (see Chiappori (1988b)) with an objective function form of $Y^{N}=\left(Y_{A}-Y_{C A}\right)\left(Y_{B^{-}} Y_{C B}\right)$, the Kalai-Smorodinsky (1975) geometrical solution or a version of the Rubinstein (1982) non-cooperative bargaining model.

The model lends itself to a useful interpretation of transaction costs. In general a collective rationality solution, that is, where the partners bargain, discuss and 
institute a form of sharing contract should emerge from this organisational game. If it does then the solution should emerge between a and $\mathrm{b}$ on the contract curve (quadrant (I))/Pareto frontier (quadrant (IV)) as these points represent Pareto improvements over the Cournot solution C. On the other hand they can just do their best given what the other player might do, a non-cooperative Nash solution and many possibilities exist for the type of Nash equilibrium achieved. This would provide an inefficient solution. The choice of cooperation versus non-cooperation is the realm of the prisoners' dilemma solution where individual rationality dominates collective rationality. Noncooperative models differ from the bargaining framework in the sense that they are sub-optimal in terms of the distribution of resources between partners. Authors have increasingly been frustrated by the lack of explanation of why individuals may take up non-cooperation (strike behaviour for example, Manzini (1998))), indeed there seems no reason why a non-cooperative solution should exist at all given that both players lose out. The prisoners' dilemma provides a partial answer to this question, see Ostrom (2000) for a discussion of collective action, whereas the transactions cost literature probably gives us a better understanding of it (Seaton (2001)). Individuals cannot necessarily police each other due to high information asymmetry/costs and set appropriate contracts, that is, high transaction costs to bargaining may lead to a breakdown to non-cooperative behaviour.

[Table 1 about here]

It is worth reflecting on the implications of this model. As an example, two partners run an organization, $R$, and must determine the ideal level of each input. If they shared a common objective function, for example maximize output given a 
certain level of expenditure, it would not matter how they behaved, with full information and common aims they would still reach the same input and output decisions, the Neoclassical Pareto optimal firm, see first row of Table 1. The picture changes dramatically if the partners hold different preferences over firms' input levels and goals, see Table 1 row two. If one partner decides all, we have a Neoclassical firm result, though depending on which partner holds the position input and output choices will be different. If however democracy prevails and some form of bargaining arrangement occurs, then again we have a Pareto optimal sharing rule. Finally noncooperation of some type would yield Pareto inefficiency. Thus by allowing a simple difference of opinion in the firm many potential models of behaviour emerge. In the next section we show that revealed preference analysis allows us to test for this. 


\section{Revealed Preference Tests of Intra-firm Rationality}

\section{Methodology}

The following material is based on the revealed preference literature notably the work of Samuelson (1938a, 1938b), Houthakker (1950), Koo (1963, 1965, 1971), Dobell (1965), Afriat (1967, 1973), Uebe (1972), Diewert (1973), and Varian (1982, 1983, 1984, 2006), Chiappori (1988a, 1988b) and Seaton (1997, 2001). Our main results are displayed in Appendix One which also explains the implementation of the testing procedure. For completeness we will define and compare two forms of behaviour, Organisational Neoclassical Rationality (ONR) and Organisational Collective Rationality (OCR). Our Neoclassical version of the model assumes that the aim of the Organisation, $R$, is the size of $Y$ where the size of $Y$ is determined purely by both players choice of business inputs $z_{A}$ and $z_{B},{ }^{2}$ the level of other inputs $z_{C}=z_{C A}+z_{C B}$, capital, buildings energy inputs etc, which are jointly bought and funded from retained earnings or loans $F=F_{A}+F_{B}$. The organisation's optimisation decision is to maximize,

$Y_{R}\left(z_{A}, z_{B}, z_{C A}, z_{C B}\right)$ s.t. $F-w_{A} z_{A}-w_{B} z_{B}-z_{C} \geq 0$,

where the price of $z_{C}$ is numeraire. Our only restriction on the form of $Y_{R}$ is that it be concave, differentiable and increasing. Note we have kept the model simple for convenience, practicality and simplicity as both quantities and prices are not so easily

\footnotetext{
${ }^{2}$ Although hours of work is an obvious candidate, both inputs could also represent the number of a particular employee type i.e. director, non-executive director, part-time or full time worker etc. This opens up a potential path of research into organizational governance issues.
} 
recovered from standard data. In this form standard consumer revealed preference tests can be used to determine the consistency of choices with ONR.

The primary argument of this paper is that there is some disagreement between the players $A$ and $B$ on the actual form of $Y$, this is very likely in the case for technological products where each player may hold specialist information, one may be the technical expert whilst the other may be the dynamic entrepreneurial driving force behind the product, in marketing for example. In this sense neither partner initially agrees on the optimal input mix. Thus two alternative forms for $Y_{R}$ are suggested; Neoclassical or uniform where $Y$ is identical between individuals, $Y_{A}=Y_{B}$ $=Y_{R}$, and represents a standard overall objective function for the organisation and the individualistic where $Y$ is different between individuals, where $i=A, B$ and some form of bargaining outcome could be achieved. This second case, our main result, is analysed later but it is worth stating that it captures altruistic effects, that player $A$ takes into account the consumption of the other player, and a special case of an egoistic objective function is $Y_{i}\left(z_{i}, z_{C i}\right), i=A, B$.

Different model forms can be suggested for these cases depending on the assumptions regarding the level of altruism, egoism on the part of the players as well as the jointness in benefit of the inputs, see table 2 below. In Chiappori (1988a), the favoured forms were (III) versus (IV). Here the third input $z_{C}$ can be separately consumed, whereas in (I) there is no individual consumption. In the case of the household this may be a more relevant scenario, however for the firm either (I) versus (II) or (V) versus (VI) might be equally plausible. In (I) and (II) $A$ and $B$ consume equal quantities of the input, a public input, which seems sensible if satisfaction is based upon some output measure. The latter case, where there is joint use of inputs, might also be relevant, especially if we talk about two separate plants, which purchase 
inputs separately (data might be available here in certain well defined studies). However, the latter cases (V) versus (VI) may be far too general to provide sufficient restrictions on behaviour, so for this analysis we restrict our cases mainly to (I) versus (II) and use (III) versus (IV) for comparison to the initial work done by Chiappori (1988a) and Seaton $(1997,2001)$.

[Table 2 - about here]

To illustrate we use model (III) from the Table 2. For convenience we change notation slightly; let

$Y=Y(Z)$, where $Z=\left(z_{A}, z_{B}, z_{C A}, z_{C B}\right)=\left(z_{1}, z_{2}, z_{3}, z_{4}\right)$ and $z_{3}=z_{4}=0.5 z_{C}$,

write an appropriate price vector for all the inputs as

$P=\left(w_{A}, w_{B}, 1,1\right)=\left(p_{1}, p_{2}, p_{3}, p_{4}\right)$.

by analogy to Chiappori/Seaton, though not critical to this paper, we consider this model represents directors $\left(z_{1}\right)$, employees $\left(z_{2}\right)$, where both enjoy some share of the input $\left(z_{3}\right)$, in terms of their belief in its contribution to output and also in their direct use of it, in the case of directors this could be use of company cars, for employees staff canteen facilities, alternatively heating and buildings are also good candidates. 


\section{Testing individual rationality (ONR)}

Consider a set $G(Z)$ of $n$ input bundles $Z^{1}, Z^{2}, Z^{3}, \ldots, Z^{n}$ where $Z^{k}=\left(z_{1}^{k}, z_{2}^{k}, z_{3}^{k}, z_{4}^{k}\right)$ from observed behaviour. Koo (1971) and Varian (1982) define $D R$ to mean directly revealed preferred where

$Z^{1}(D R) Z^{2}$ if $P^{l} Z^{1} \geq P^{l} Z^{2}$

As DR is a binary relationship, Koo (1971) showed that for a finite group $G(Z)$ of input bundles a Boolean matrix could be constructed to yield a summary of the agents preference structure over some observed input bundles, see appendices.

Further we can compare data for consistency with the following alternative axioms of preference theory.

ONRWARP $=\left\{\right.$ If $Z^{i}(D R) Z^{j}$ then not $Z^{j}(D R) Z^{i}$ for $\left.Z^{i} \neq Z^{j}\right\}$

$O N R G A R P=\left\{\right.$ If $Z^{i}(R) Z^{j}$ then not $P^{i} Z^{i}>P^{i} Z^{j}$ for $\left.Z^{i} \neq Z^{j}\right\}$

ONRSARP $=\left\{\right.$ If $Z^{i}(R) Z^{j}$ then not $Z^{j}(R) Z^{i}$ for $\left.Z^{i} \neq Z^{j}\right\}$,

\section{Tests of collective rationality (OCR)}

Following Varian (1984, p 590 Theorem 11), Chiappori(1988a) and Seaton(1997, 2001) and arguing that some form of bargaining compromise (sharing rule, see Chiappori (1988a)) is reached then partners optimise,

$Y_{R}=a_{A} Y_{A}\left(z_{A}, z_{B}, z_{C A}, z_{C B}\right)+a_{B} Y_{B}\left(z_{A}, z_{B}, z_{C A}, z_{C B}\right)$, 
where $a_{A}, a_{B} \geq 0, a_{A}+a_{B}=1, a_{i}=a_{i}\left(w_{A}, w_{B}, F_{A}, F_{B}, X_{A}, X_{B}\right), i=A, B$ and $\left(X_{A}, X_{B}\right)$ represents characteristics of the players. OCRWARP,OCRGARP and OCRSARP can be written in a similar way to their ONR analogues excepting that they must take into account now two restrictions, each based upon the personal prices for each group, as well as taking into account the jointness, if any, assumed in the inputs, see Appendix One for details. It is worth noting that ONR is a special case of OCR when either $a_{A}=a_{B}=0.5$ or one $a_{i}$ is zero.

\section{Examples and Results}

In all four examples below firms were selected where they reported sales, depreciation, employment, number of directors, director remuneration, total remuneration and operating profit. The measure of total expenditure is total sales minus operating profit plus depreciation and the cost of each input is calculated in a simplified manner. The cost of a director is simply the average directors' remuneration, whilst employees' wages are calculated in a similar way.

\section{Example One: Morgan Crucible Plc}

Let us consider some data from Morgan Crucible Plc over the years 2000 to 2004, presented in Table A1.1 of the Appendix Two. Here we must deflate all prices by an appropriate input price index. From our analysis the data from Morgan Crucible are entirely consistent with all axioms, ONRWARP, ONRGARP, ONRSARP and therefore OCRWARP, OCRGARP and OCRSARP. As this data is consistent with that of the Neoclassical organisation (ONR), how do we interpret these results? Either the objectives of the organization are so firmly held in stone and agreed by decision 
makers that bargaining is not a relevant modelling outcome or that a dictatorship point like $D_{A}$ in figure 2 exists.

\section{Example Two: Multinational corporations industry wide.}

A heterogeneous sample of very large firms were derived in a sample of 92 quoted companies from the Datastream (Worldscope) database in different industries with sales in the US, Europe and the UK over a period of at least 14 years, sampled in the year 2003. There were no restrictions placed on industry, employees etc. Indeed heterogeneity was the desired goal. In this sense it is expected that a high degree of inconsistency should be found with ONR. In reality the number of inconsistencies with ONRWARP and ONRSARP are 36 (less than 1\%) and 48 (less than 1\%) respectively, which does not seem particularly high. However, testing for OCR (see table 3) also finds inconsistency with the Pure input form, both SARP and WARP. This indicates complicating factors emerge in this group of firms, which we discuss later. However the data are consistent with the Joint version of all OCR axioms and the Pure realisation of OCRGARP. This points to the possibility that individuals are unable to have much impact on firm objectives.

\section{Example Three : The computer industry}

In total the FAME database holds 2228 companies in the 4-digit SIC category 3002, the manufacture computers and other information processing equipment, this includes 2058 identifiable public and private limited companies of which 22 are public limited. After selecting on our desired variables a sample of 107 firms remained. We find as before that there is inconsistency with ONR. In fact 180 for ONRWARP (just 1\%) 
and 1044 for ONRSARP (5\%) which is a great deal higher than we expected from the previous example as these firms derive from the same industry with the same accounting years. Just as with Example Two we find inconsistency with Pure OCR but consistency with Joint OCR.

[Table 3 - about here]

\section{Example Four: The computer industry, sub-sampled by size}

For a more in depth analysis of the data presented in example three the sample of 107 companies is split into sub-samples of 30 then 50 firms by size of firm. Thus the first sample of 30 firms would consist of the smallest 30 firms. The second sub-sample would contain the same firms except the smallest would be replaced by the $31^{\text {st }}$ smallest. This sampling progresses until the final sub-sample which would contain the top 30 largest firms.

Sub-samples of size 30 and 50 violate all ONR axioms as with examples two and three. Interestingly the number of inconsistencies displayed in figures 3 and 5, by size of firm in each sub-sample, indicate a rise in inconsistency until a peak for medium sized firms, falling off for large firms. This is represented by a U-shaped trough for the 'Goodness of fit' measure used (see note to Table 3).

[Figure 3 about here]

The tests of inconsistency with OCR (Pure version) were very surprising. Here, see figures 4 and 6, small to medium firms appear to have behaved consistently with the OCR hypothesis of bargaining behaviour. However, the larger firms did not. 
On the plus side the data are consistent in all cases with the joint third input model and the Pure OCRGARP axiom.

[Figure 4 about here]

The results together appear to indicate that intra-firm resource allocation is determined by a successful bargaining form between the key decision makers in small to medium firms. Increasing further the size of firm tends to bring in complicating features that are not assumed in the bargaining model. There are many possible factors. First, bargaining may be failing to some form of non-cooperation (increasing transactions costs i.e. policing and information failure) as discussed in previous sections. Second, a much wider set of individuals/group might be involved in the bargaining situation (shareholders, directors, managers, other employees (trade unions)).

[Figure 5 about here]

[Figure 6 about here] 


\section{Concluding Comments}

The aims of this paper were twofold. First to show that the firm could be viewed as an organization where decision makers can hold differences of opinion and, secondly, to produce a workable test of organisational form. Given this interpretation of the firm, revealed preference methods for examining the implications of aggregated behaviour were presented. Four examples with three different sample types indicate the applicability of these methods and provide some explanation of apparent inconsistency with traditional Neoclassical techniques (ONR).

The key conclusion from the brief application of this methodology is that smaller firms (at least in the computing industry) appear to possess cooperative decision making behaviour though larger firms may not. The failure of some data to fulfil the restrictions imposed by the OCR model is in some sense absolute, though none failed OCRGARP in any examples. The cause of failure may be the existence of more than two decision making groups, aggregation of inputs and also whether there are competitive labour markets, as well as the comparability of firms in each sample.

The main contribution of this work is that we now have a methodology that allows us to filter data for potential governance implications on input demand as Seaton (2001) shows for the household organisation. In this sense we can analyse whether hierarchy/governance may be failing to allow decision makers to realize their goals. Although this paper has been directed at determining inconsistency with the underlying model, further work should also be targeted at the implications for restrictions on input demand functions as this is a fairly straightforward application of Chiappori's (1988a) contribution. 


\section{References}

Afriat, S. N. (1967) The construction of utility functions from expenditure data, International Economic Review, 8, 67-77.

Afriat, S. N. (1973) On a system of inequalities in demand analysis: an extension of the classical method, International Economic Review, 14, 460-72.

Antle, R. and Fellingham, J. (1990) Resource rationing and organizational slack in a two-period model, Journal of Accounting Research, 28, 3-24.

Bourguinon, F. and Chiappori, P. A. (1992) Collective models of household behaviour, European Economic Review, 36, 355-64.

Browning, M. and Chiappori, P. A. (1998) Efficient intra-household allocations: a general characterization and empirical tests, Econometrica, 66, 1241-78.

Chiappori, P. A. (1988a) Rational household labor supply, Econometrica, 56, 63-89.

Chiappori, P.A. (1988b) Nash-bargained households decisions: a comment, International Economic Review, 29, 791-96.

Dasgupta, I. (2005) Consistent firm choice and the theory of supply, Economic Theory, 26, 167-75.

Diewert, W.E. (1973) Afriat and revealed preference theory, The Review of Economic Studies, 40, 419-25.

Dobell, A. R. (1965) A comment on A.Y. Koo's: an empirical test of revealed preference theory, Econometrica, 33, 451-55.

Fama, E. (1980) Agency problems and the theory of the firm, The Journal of Political Economy, 88, 288-307.

Famulari (1995), A household-based, non-parametric test of demand theory, The Review of Economics and Statistics, 77, 372-82.

Fortin, B. and Lacroix, G. (1997) A test of the unitary and collective models of household labour supply, The Economic Journal, 107, 933-55.

Green, H. A. J. (1976) Consumer Theory Revised Edition, The MacMillan Press Ltd, London and Basingstoke.

Houthakker (1950), Revealed Preference and the utility function, Economica New Series, 17, 159-74.

Kalai, E. and Smorodinsky, M. (1975) Other solutions to Nash's bargaining problem, Econometrica, 43, 513-8. 
Koo, A. Y. C. (1963) An empirical test of revealed preference theory, Econometrica, 31, 646-64.

Koo, A. Y. C. (1965) Reply, Econometrica, 33, 456-8.

Koo, A. Y. C. (1971) Revealed preference - a structural analysis, Econometrica, 39, 89-97.

Leibenstein, H. (1966) Allocative efficiency and x-efficiency, The American Economic Review, 56, 392-415.

Leuthold, J.E. (1968) An empirical study of formula income transfers and the work decision of the poor, Journal of Human Resources, 3, 312-23.

Magee, R. P. (1988) Variable cost allocation in a principle/agent setting, The Accounting Review, 63, 42-54.

Manser, M. and Brown, M.(1980) Marriage and household decision making: a bargaining analysis, International Economic Review, 21, 31-44.

Manzini, P. (1998) Game theoretic models of wage bargaining, Journal of Economic Surveys, 12, 1-41.

McElroy, M.B. and Horney, M.J. (1981) Nash - bargained household decisions: toward a generalization of the theory of demand, International Economic Review, 22, 333-49.

Nash, J. (1950) The Bargaining Problem, Econometrica, 18, 155-62.

Nash, J. (1951) Two-person cooperative games, Econometrica, 21, 128-40.

Ostrom, E. (2000) Collective action and the evolution of social norms, Journal of Economic Perspectives, 14, 137-58.

Romer, D. (2006) Do firms maximize? Evidence from professional football, Journal of Political Economy, 114, 340-65.

Rubinstein, A. (1982) Perfect equilibrium in a bargaining model, Econometrica, 50, 97-110.

Samuelson (1938a), A note on the pure theory of consumer's behaviour, Economica New series, 5, 61-71.

Samuelson (1938b), A note on the pure theory of consumer's behaviour- an addendum, Economica New series, 5, 353-4.

Seaton, J. S. (1997) Neoclassical and collective rationality in household labour supply, Applied Economics Letters, 4, 529-33. 
Seaton, J. S. (2001) Bargaining versus non-cooperation; transactions costs within marriage, Applied Economics Letters, 8, 37-41.

Uebe, G. (1972) A note on Anthony Y.C.Koo, "Revealed preference - A structural Analaysis", Econometrica, 40, p. 771.

Varian, H. R. (1982) The nonparametric approach to demand analysis, Econometrica, 50, 945-73.

Varian, H. R. (1983) Non-parametric tests of consumer behaviour, Review of Economic Studies, 50, 99-110.

Varian, H. R. (1984) The Nonparametric Approach to Production Analysis, Econometrica, 52, 579-98.

Varian, H. R. (1999) Intermediate Microeconomics: A Modern Approach, $5^{\text {th }}$ Edition, W.W. Noton \& Company, New York, ISBN 0-393-97370.

Varian, H. R. (2006) Revealed preference, http://www.sims.berkeley.edu/ hal/Papers/2005/revpref.pdf

Vermeulen, F. (2002) Collective household models: principles and main results, Journal of Economic Surveys, 16, 533-64. 


\section{Appendix One: Derivations}

\section{Organisational Neoclassical Rationality (ONR)}

Following the analysis of Koo (1971) where the group $G(Z)$ is restricted to 5 input bundles, $G(Z)=\left[Z^{1}, Z^{2}, Z^{3}, Z^{4}, Z^{5}\right]$ the matrix of expenditure differences $\left(P^{i} Z^{i}-P^{i} Z^{j}\right)$ are easily calculated, see Table A1.2 in the examples appendix. From these define the $i j^{\text {th }}$ element of $M$, an $n$ by $n$ Boolean matrix as

$m_{i j}=1$ if $P^{i} Z^{i} \geq P^{i} Z^{j}$, that is if $Z^{i}(D R) Z^{j}$.

The matrix $M$ can be summarized by the use of directed graphs or digraphs. That is, for the square $(n \times n)$ Boolean matrix $M$, the digraph, $D(M)$, consists of points or vertices $V_{l}, V_{2}, \ldots, V_{n}$ and lines or edges $V_{i} V_{j}$ which exist if $m_{i j}=1$ but not if $m_{i j}=0$ in $M$. Our data in $M$ is now shown in the digraph in Figure A1.

[Figure A1 about here]

Our question is whether this data appear to satisfy consistency of choice as a single organisation. Here we introduce a number of key axioms, from Varian (1982), the Weak Axiom of Revealed Preference (WARP) is defined in the following way, if $Z^{i}$ is directly preferred to $Z^{j}$ then bundle $j$ cannot be preferred to bundle $i$, or

$W A R P=\left\{\right.$ If $Z^{i}(D R) Z^{j}$ then $\operatorname{not} Z^{j}(D R) Z^{i}$ for $\left.Z^{i} \neq Z^{j}\right\}$

This relation is also known as an acyclic strict order relation. It is worth looking at a violation of WARP in the following example 


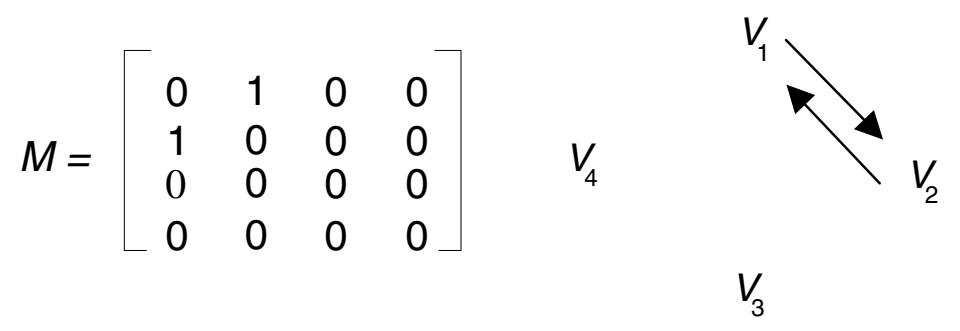

Note the cycle from $V_{1}$ to $V_{2}$ and back to $V_{l}$, the digraph is not Acyclic and is a clear violation of WARP.

The next example possesses a cycle, but is not a violation of WARP. Here we need a stronger argument to capture this apparent inconsistency in choice.

$M=\left[\begin{array}{llll}0 & 1 & 0 & 0 \\ 0 & 0 & 1 & 0 \\ 1 & 0 & 0 & 0 \\ 0 & 0 & 0 & 0\end{array}\right]$

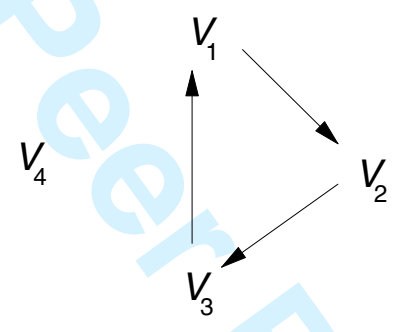

(A4)

For this reason a second axiom called the Strong Axiom of Revealed Preference was suggested, and defined as,

$S A R P=\left\{\right.$ If $Z^{i}(R) Z^{j}$ and $Z^{i} \neq Z^{j}$ implies not $\left.Z^{j}(R) Z^{i}\right\}$,

where Revealed preferred $(R), Z^{i}(R) Z^{j}$ means for some sequence of observations $\left(Z^{i}\right.$, $\left.Z^{k}, Z^{l}, Z^{m}, Z^{j}\right) . Z^{i}(R) Z^{j}$ : If $P^{i} Z^{i} \geq P^{i} Z^{k}, P^{k} Z^{k} \geq P^{k} Z^{l}, P^{l} Z^{l} \geq P^{l} Z^{m}, P^{m} Z^{m} \geq P^{m} Z^{j}$. We say here that $(R)$ is the transitive closure of the relation $(D R)$, and can be written as,

$Z^{i}(R) Z^{j}$ : If $Z^{i}(D R) Z^{k}, Z^{k}(D R) Z^{l}, Z^{l}(D R) Z^{m}, Z^{m}(D R) Z^{j}$. 
In this sense the data above are inconsistent with SARP because it is not acyclic, the cycle exists from $V_{1}, V_{2}$ to $V_{3}$ and back to $V_{l}$.

However, another case with for example $Z^{1}(D R) Z^{2}$ and $Z^{3}(D R) Z^{1}$ shows the strength of the SARP axiom, consider the Boolean matrix and digraph below, where, again WARP is satisfied.

$M=\left[\begin{array}{lll}0 & 1 & 0 \\ 0 & 0 & 0 \\ 1 & 0 & 0\end{array}\right]$

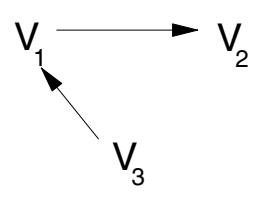

But if we note that through transitivity $Z^{3}(D R) Z^{1}, Z^{1}(D R) Z^{2}$ implies that $Z^{3}(R) Z^{2}$ represented in the new Boolean matrix $\mathrm{M}^{*}$ with a star and digraph as the dotted arrow.

$M^{*}=\left[\begin{array}{lll}0 & 1 & 0 \\ 0 & 0 & 0 \\ 1 & 1^{*} & 0\end{array}\right]$

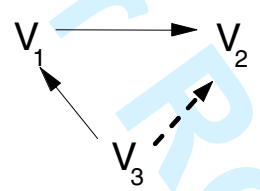

We complete this discussion by looking at a final axiom, which is less restrictive than SARP but does take into account transitivity, the Generalized Axiom of Revealed Preference can be written as,

$G A R P=\left\{\right.$ If $Z^{i}(R) Z^{j}$ implies not $\left.Z^{j}(S D R) Z^{i}\right\}$, where Strictly Directly Revealed Preferred $(S D R)$, is represented by $Z^{i}(S D R) Z^{j}$ : If $P^{i} Z^{i}>P^{i} Z^{j}$

Consequently if $m_{i j}^{*}=1$ and $P^{j} Z^{j}>P^{j} Z^{i}$ then GARP is violated. 


\section{Organisational Collective Rationality (OCR)}

We can rewrite expression $Y$ and perform some convenient relabelling, let players,

$A=1, B=2$ and $Z=\left(z_{A}, z_{B}, z_{C A}, z_{C B}\right)=\left(z_{1}, z_{2}, z_{3}, z_{4}\right)$, thus

$Y=a_{1} Y_{1}(Z)+a_{2} Y_{2}(Z)$

we can also write an appropriate price vector for all the inputs as

$P=\left(w_{A}, w_{B}, 1,1\right)=\left(p_{1}, p_{2}, p_{3}, p_{4}\right)$

So $p_{q}$ represents the price of input $z_{q}$ where $q=1,2,3,4$. Following Chiappori (1988) and Seaton (1997) if we observe a mix $Z^{j}, j=1,2, \ldots, N$ is chosen then $Z^{j} P^{j} \geq Z P^{j}$

It is revealed preferred to all other affordable $\mathrm{Z}$. The general firm level bargaining optimisation problem can be expressed as,

$\Lambda=a_{1}^{j} Y_{1}(Z)+a_{2}^{j} Y_{2}(Z)+\lambda^{j}\left(Z^{j} P^{j}-Z P^{j}\right), \quad j=1,2, \ldots, N$.

Differentiating with respect to individual $i$ 's desired input of $q$ we get

$a_{1}^{j} Y_{1 i q}+a_{2}^{j} Y_{2 i q}=\lambda^{j} p_{q}^{j}, \quad j=1,2, \ldots, N$ 
dividing this expression through by $\lambda^{j}$ and noting that the new expression simply stated uses the additive separability of the individual utility functions to split the value of price to individual level shadow/personal prices, the expression can be rewritten as

$\theta^{j}{ }_{i q} p_{q}^{j}+\left(1-\theta^{j}{ }_{i q}\right) p_{q}^{j}=p_{q}^{j}, \quad j=1,2, \ldots, N$, and $\theta^{j}{ }_{i q} \geq 0$

We require for each individual that each set of personal prices, $\theta$, and quantities satisfy individual rationality. So for collective rationality to be true here, both individual rationalities must be satisfied given the nature of the choices made and values of the shadow prices $\left(\theta^{j}{ }_{i q} p_{q}^{j},\left(1-\theta^{j}{ }_{i q}\right) p_{q}^{j}\right)$, though aggregate prices and input quantities may not.

\section{OCR Implementation}

Tests for the rationality of choices for one individual given prices and bundles chosen are straightforward to do using revealed preference techniques. As we typically possess data regarding quantities of inputs, then the form of $Z$ is typically known. Similarly we also normally possess information as to the value of input prices. However we do not know the individual valuation $(\theta)$ put on these inputs by the bargainers. All we do know are their bounds $(p \geq p \theta \geq 0)$. Further we cannot perceive the individual levels of inputs selected by the individuals except of course number of employees, $\left(z_{1}, z_{2}\right)$. 
For the moment let us proceed as if we do know these values. For each observation $j, k=1 \ldots N$ we can construct two Boolean matrices representing the preference choices for $i=A, B$ respectively depending on the personal prices they possess. That is

$M^{j k}{ }_{i}=1$ if $\rho_{i}^{j}\left(Z^{j}-Z^{k}\right) \geq 0$ otherwise $M^{j k}{ }_{i}=0$

where $\rho_{A}^{j}=\left(\theta^{j}{ }_{A 1} p_{1}{ }^{j}, \theta^{j}{ }_{A 2} p_{2}{ }^{j}, \theta^{j}{ }_{A 3} p_{3}{ }^{j}, \theta^{j}{ }_{A 4} p_{4}{ }^{j}\right)=\left(\theta^{j}{ }_{A 1} w_{A}{ }^{j}, \theta^{j}{ }_{A} w_{B}{ }^{j}, \theta^{j}{ }_{A 3}, \theta^{j}{ }_{A 4}\right)=$

$$
\text { and } \begin{aligned}
\rho_{B}{ }_{B} & =\left(\left(1-\theta^{j}{ }_{A 1}\right) p_{1}{ }^{j},\left(1-\theta^{j}{ }_{A 2}\right) p_{2}{ }^{j},\left(1-\theta^{j}{ }_{A 3}\right) p_{3}{ }^{j},\left(1-\theta^{j}{ }_{A 4}\right) p_{4}{ }^{j}\right) \\
& =\left(\left(1-\theta^{j}{ }_{A 1}\right) w_{A}{ }^{j},\left(1-\theta_{A 2}^{j}\right) w_{B}^{j},\left(1-\theta^{j}{ }_{A 3}\right),\left(1-\theta^{j}{ }_{A 4}\right)\right)
\end{aligned}
$$

and $Z=\left(z_{A}, z_{B}, z_{C A}, z_{C B}\right)$

as the data on individual quantities of $z_{C}$ may only exist in aggregated form we introduce another parameter to indicate that the division is unknown, thus

$z_{C}^{j}=\theta^{j}{ }_{A 5} z_{C A},+\left(1-\theta^{j}{ }_{A 5}\right) z_{C B}$

The final result of our comparison with personal prices is the two Boolean matrices

$M_{A}^{j k}$ and $M_{B}^{j k}$ where $j, k=1 \ldots N$

As the parameters $\theta^{j}{ }_{A 1}, \theta^{j}{ }_{A 2}, \theta^{j}{ }_{A 3}, \theta^{j}{ }_{A 4}, \theta^{j}{ }_{A 5}, j=1,2, \ldots N$ are unknown, trial values can be inserted to minimize the number of $\mathrm{CR}$ inconsistencies. For a few observations (3 say) this is a trivial exercise, but for large $\mathrm{N}$ then $5 \mathrm{~N}$ parameters must be searched and the problem becomes highly intractable. Searching 5 parameters over 7 values for $\mathrm{N}$ observations gives $7^{5 \mathrm{~N}}$ trials (for 10 observations $7^{50} \approx 1.798 \times 10^{42}$, if each trial took 
one billionth of a second to calculate it would still take centuries to check each trial). So some simplification was needed especially for samples sizes of $\mathrm{N}=50$ or more.

A two stage method was used here to take account of similarities and differences of parameters across observations, remember that the Neoclassical model assumes all parameters are fixed at 0.5 for all observations, so we are allowing a high degree of flexibility in the search.

Stage 1. Capture parameter homogeneity across observations.

A grid search fixing $\theta^{j}{ }_{A 1}, \theta^{j}{ }_{A 2}, \theta^{j}{ }_{A 3}, \theta^{j}{ }_{A 4}, \theta^{j}{ }_{A 5}$ for all $\mathrm{j}$ to $\theta_{A 1}, \theta_{A 2}, \theta_{A 3}, \theta_{A 4}, \theta_{A 5}$ and varying these between 0 and 1 inclusive. For example if we try out values $0,0.5$ and 1

[Table A1 here]

Note there is a symmetry here, trial 1 is equivalent to trial $3^{5}$. (we need only do half the trials).

If $\omega+1$ values chosen, $0,1 / \omega, 2 / \omega, \ldots, \omega / \omega$, then $\left((\omega+1)^{5}-1\right) / 2$ combinations or if $\omega=7$ then $(16807-1) / 2=8403$ trials need to be made. However it was seen that for most data $\omega=2$ seemed adequate. We checked that no Boolean matrix collapsed to a null, none did.

Stage 2. To capture observational heterogeneity.

A grid search for each observation at a time $\theta^{j}{ }_{A 1}, \theta^{j}{ }_{A 2}, \theta^{j}{ }_{A 3}, \theta^{j}{ }_{44}, \theta^{j}{ }_{A 5}, j=1,2, \ldots N$ was carried out for the same $\omega+1$ values. For $N$ observations this means $N(\omega+1)^{5}$ 
combinations and a total of $(\mathrm{N}+1)(\omega+1)^{5}$ combinations for both stages. Stage 2 was repeated $\sigma$ number of times. Thus $(\sigma \mathrm{N}+1)(\omega+1)^{5}$ trials altogether.

The OCRWARP test to determine (for each parameter search) whether for all $k$ and $j$ that for individuals/groups $A, B$, is

If $M_{A}^{j k}=1$ implies not $M^{k j}{ }_{A}=1$ and $j \neq k$

and

If $M_{B}^{j k}=1$ implies not $M_{B}^{k j}=1$ and $j \neq k$

in which case the data does not conflict with that particular realization of the bargaining model for. A failure to find any parameter values that satisfy individual rationality for each matrix would imply some deviation from the bargaining model i.e. non-cooperative behaviour. Note this is a weak axiom of revealed preference (WARP) realisation of the problem, SARP and GARP can also be introduced in the form

If $M_{A}^{* j k}=1$ implies not $M_{A}^{* k j}=1$ and $j \neq k$

and If $M^{* j k}{ }_{B}=1$ implies not $M^{* k j}{ }_{B}=1$ and $j \neq k$

for OCRSARP, and thus for OCRGARP, both

If $M^{* j k}{ }_{A}=1$ implies not if $\rho_{A}^{j}\left(Z_{A}^{j}-Z_{A}^{k}\right)>0=1$ and $j \neq k$

and if $M_{B}^{* j k}=1$ implies not if $\rho_{B}\left(Z_{B}^{j}-Z_{B}^{k}\right)>0=1$ and $j \neq k$. 


\section{Appendix Two}

Example 1: Morgan Crucible PIc, 2000-2004

[Tables A2 to A4 here] 
Figure 1. The Aggregation Problem for A and B (Adapted from Green (1976), p. 144)

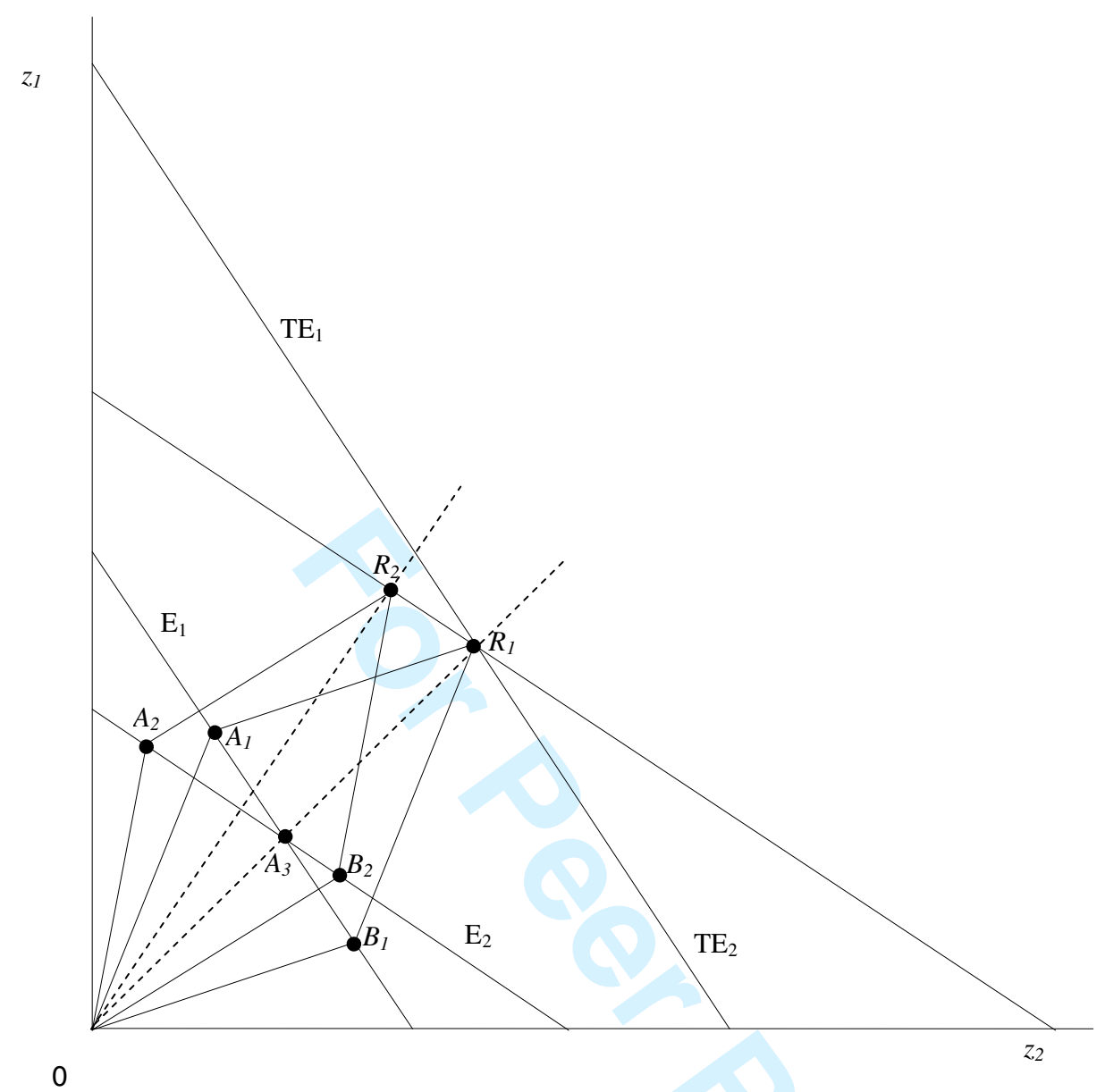

Editorial Office, Dept of Economics, Warwick University, Coventry CV4 7AL, UK 
Figure 2. Comparison of models

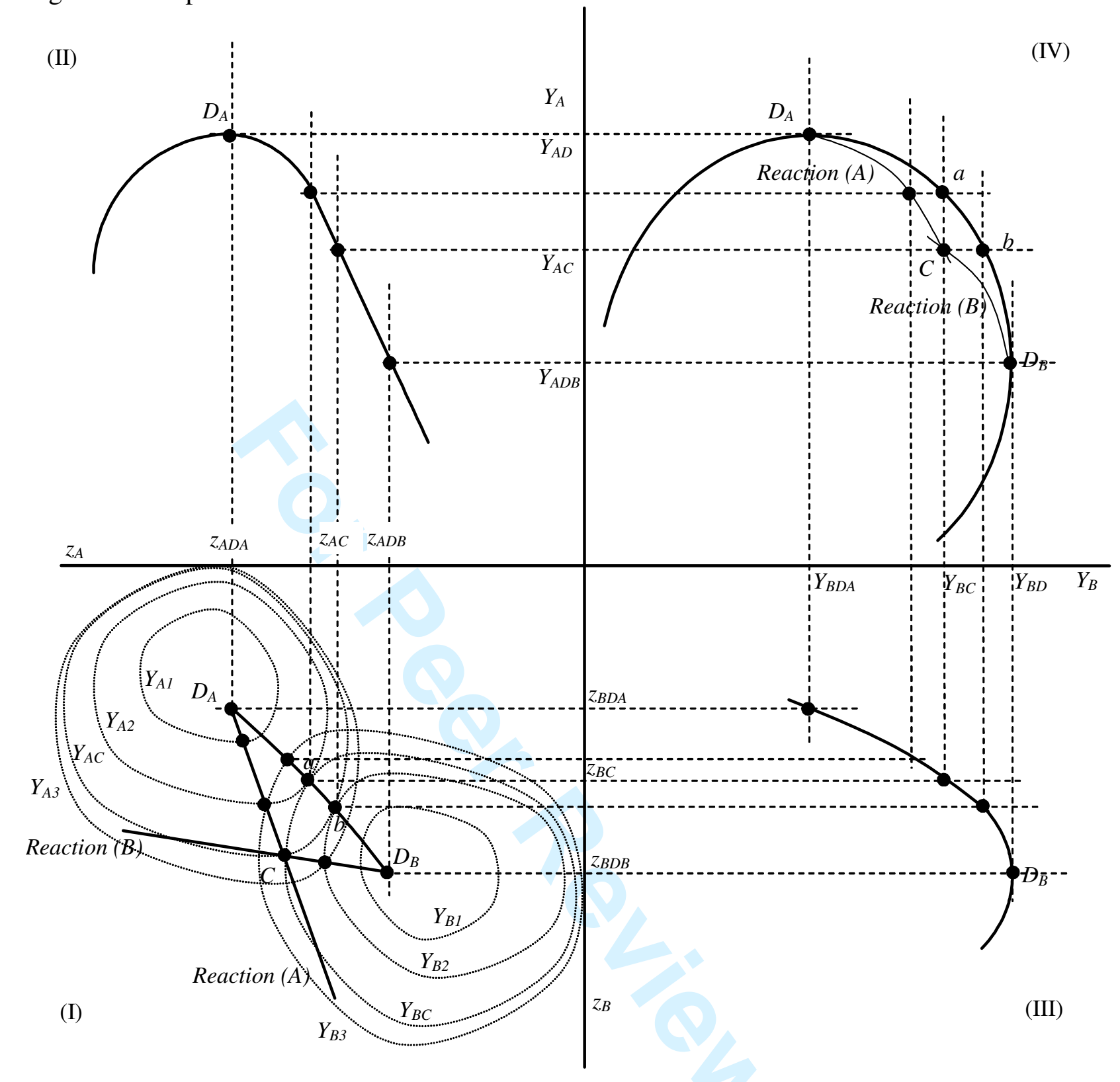


Figure 3. ONR Goodness of fit for Example Four

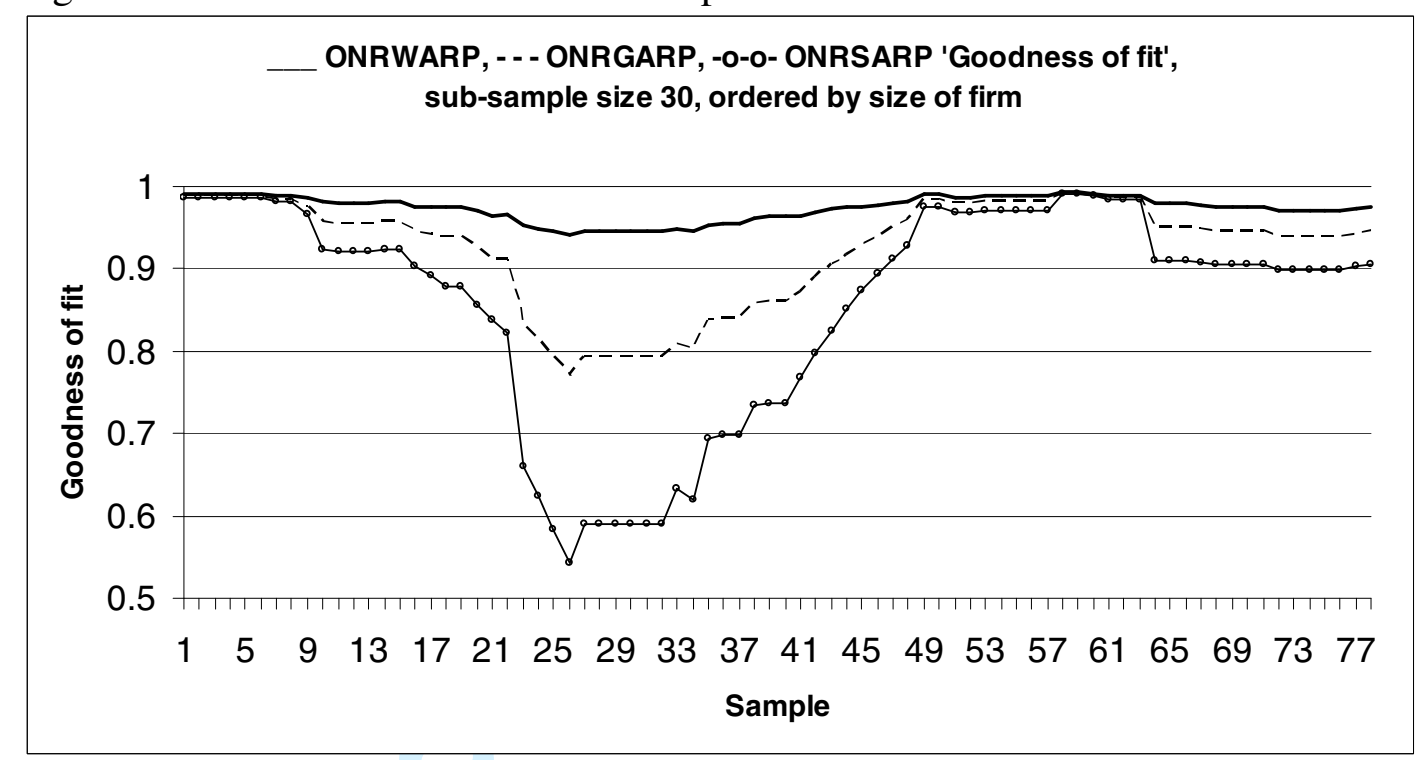


Figure 4. OCR Goodness of fit for Example Four, note GARP =1 throughout

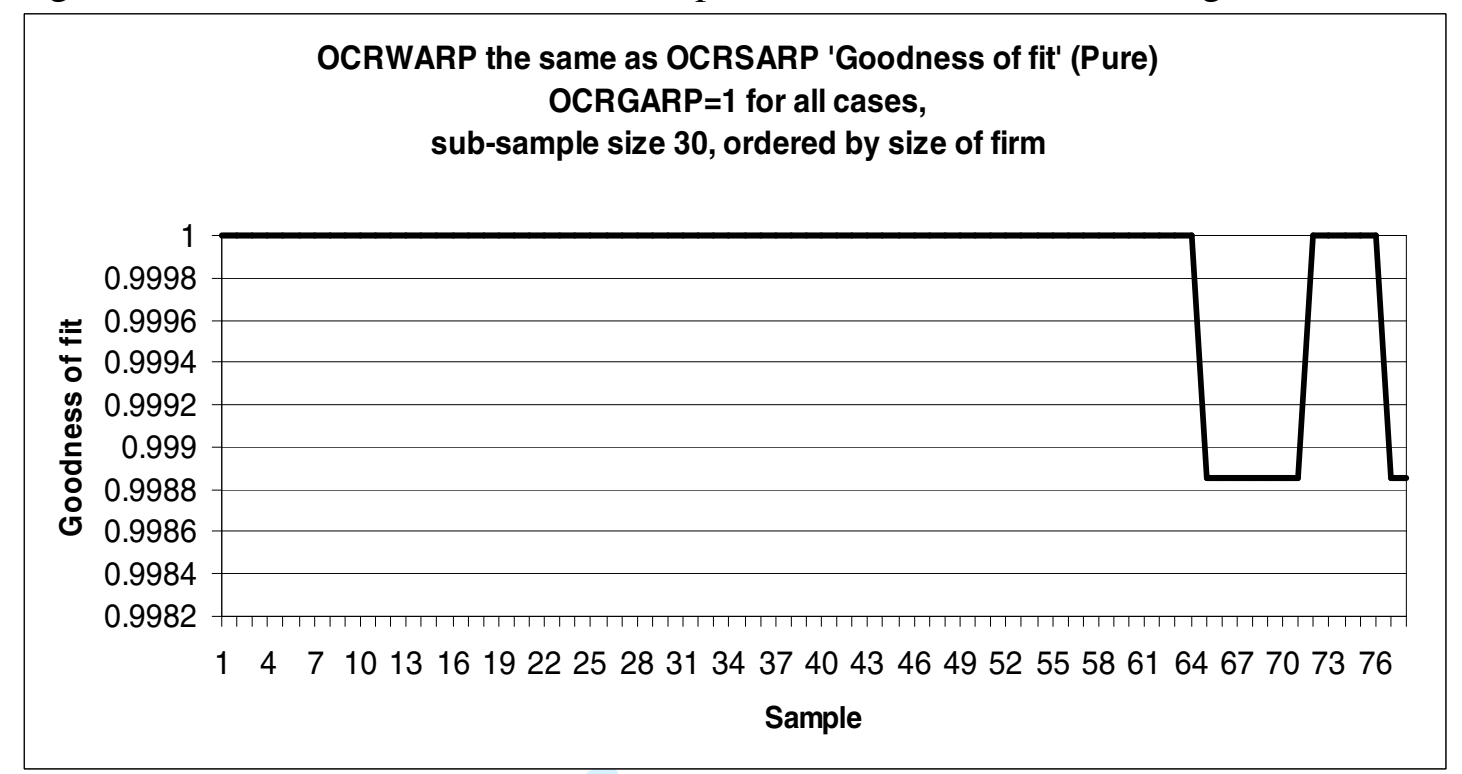


Figure 5. ONR Goodness of fit for Example Four, Sub sample size=50

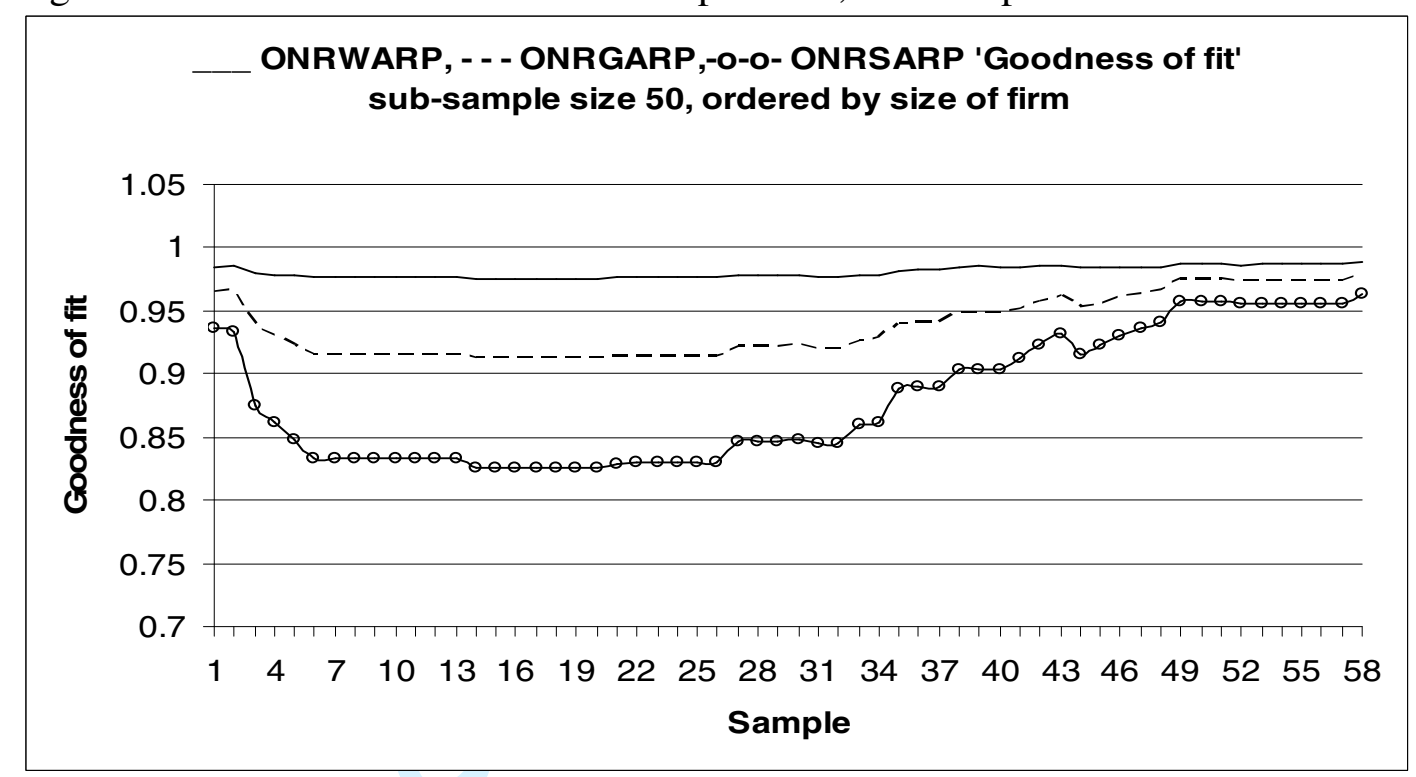


Figure 6. OCR Goodness of fit for Example Four, note GARP =1 throughout, subsample size $=50$.

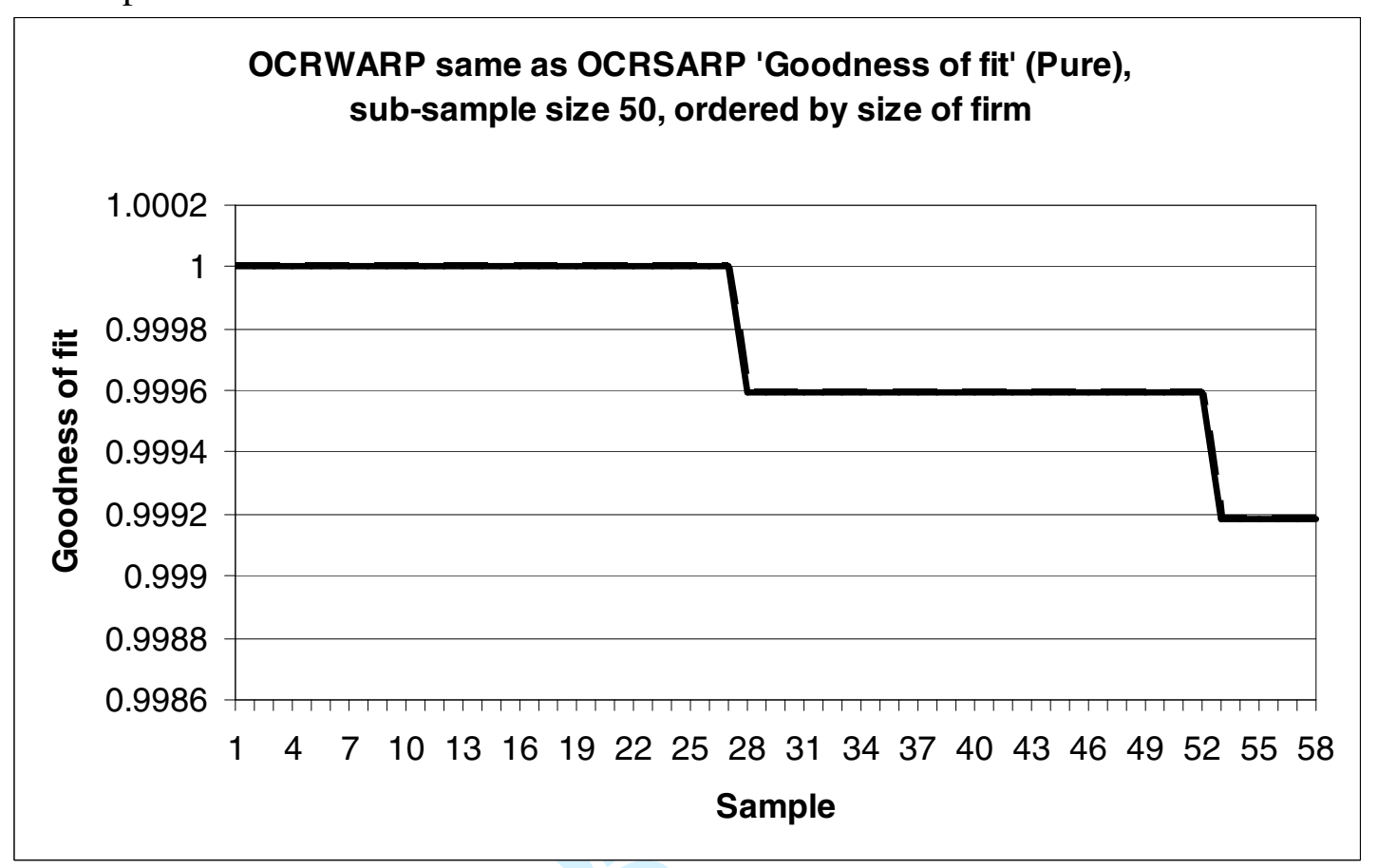


Figure A1. Digraph of Morgan Crucible's preferences

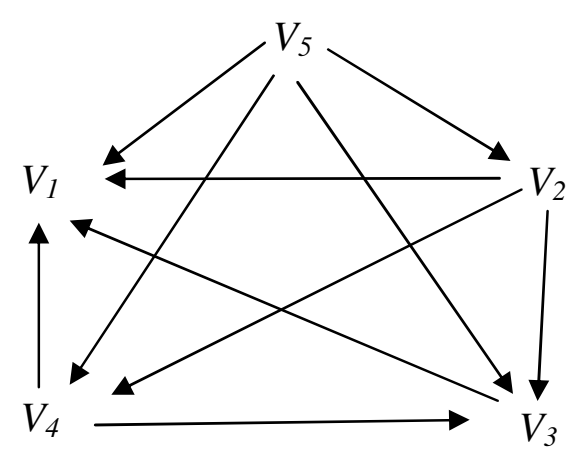


Table 1. Governance and difference of opinion

\begin{tabular}{|c|c|c|c|}
\hline $\begin{array}{l}\text { Objectives } \\
\text { (preferences) }\end{array}$ & $\begin{array}{c}\text { Governance } \\
\text { and institutional } \\
\text { relationships }\end{array}$ & & \\
\hline & $\begin{array}{c}\text { Autocracy } \\
\text { Dictatorship }\end{array}$ & $\begin{array}{l}\text { Democracy } \\
\text { Bargaining } \\
\end{array}$ & $\begin{array}{c}\text { Anarchic } \\
\text { Non-cooperative }\end{array}$ \\
\hline Homogeneous & $\begin{array}{c}\text { Neoclassical } \\
\text { Pareto Optimal } \\
\text { (One solution, } Y^{R} \text { ) }\end{array}$ & $\begin{array}{c}\text { Neoclassical } \\
\text { Pareto Optimal } \\
\left(\text { One solution, } Y^{R}\right)\end{array}$ & $\begin{array}{c}\text { Neoclassical } \\
\text { Pareto Optimal } \\
\left(\text { One solution } Y^{R}\right)\end{array}$ \\
\hline Heterogeneous & $\begin{array}{c}\text { Neoclassical } \\
\text { Pareto Optimal } \\
\text { (Two solutions } \\
\left.D_{B}, D_{A}\right)\end{array}$ & $\begin{array}{l}\text { Pareto Optimal } \\
\text { (Complex, many } \\
\text { solutions } \\
\text { depending on } \\
\text { bargaining power } \\
\text { or Nash } Y^{N} \text { ) }\end{array}$ & $\begin{array}{l}\text { Pareto Inefficient } \\
\text { (Complex, } \\
\text { many solutions, like } \\
\text { Cournot C) }\end{array}$ \\
\hline
\end{tabular}


Table 2. Alternative objective functions for decision makers in the firm

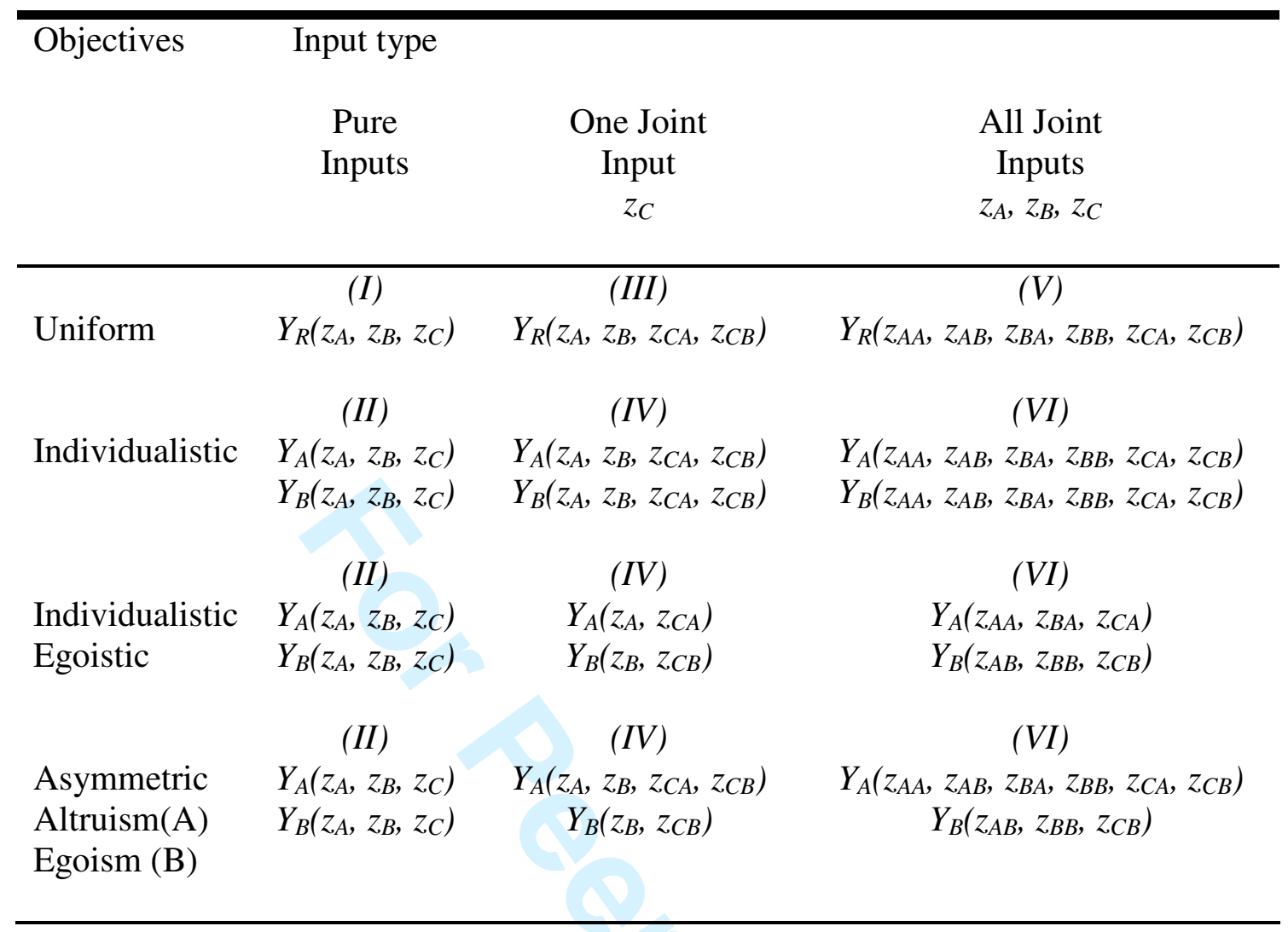


Table 3. Goodness of fit

\begin{tabular}{lccc}
\hline Goodness of fit & Example & & \\
& $\begin{array}{c}\text { Morgan } \\
\text { Crucible } \\
(N=5)\end{array}$ & Multinationals & Computing \\
Axiom & 1 & $0.9978(36)$ & $(N=107)$ \\
\hline ONRWARP & 1 & $0.9977(38)$ & $0.9921(180)$ \\
ONRGARP & 1 & $0.9971(48)$ & $0.9757(550)$ \\
ONRSARP & 1 & $0.9998(4)$ & $0.9998(104)$ \\
OCRWARP (Pure) & 1 & 1 & 1 \\
OCRGARP (Pure) & 1 & $0.9998(4)$ & $0.9998(4)$ \\
OCRSARP (Pure) & 1 & 1 & 1 \\
OCRWARP (Joint) & 1 & 1 & 1 \\
OCRGARP (Joint) & 1 & 1 & 1 \\
OCRSARP (Joint) & 1 & 1 & 1 \\
\hline
\end{tabular}

Note: These measures of goodness of fit should not be confused with those encountered in econometrics and statistics as they refer to some suggestions in the revealed preference literature. Essentially any inconsistency means failure, however authors such as Varian (2006) feel that useful information can be gleaned from investigation the inconsistencies further. For a short survey of goodness of fit measures see Varian (2006). We use the formula (TPI-TI)/TPI where TPI is the Total Possible Inconsistencies $\left(2\left(N^{2}-N\right)\right)$ from two unit matrices (both groups) and TI is the Total of Inconsistencies found, Famulari (1995), Varian (2006). Thus a value of unity implies no inconsistencies, below unity means the data is inconsistent but provides a feel for how bad it is. 
Table A1. Parameter trial values

\begin{tabular}{|l|l|l|l|l|l|}
\hline Trial & $\theta_{A 1}$ & $\theta_{A 2}$ & $\theta_{A 3}$ & $\theta_{A 4}$ & $\theta_{A 5}$ \\
\hline 1 & 0 & 0 & 0 & 0 & 0 \\
\hline 2 & 0.5 & 0 & 0 & 0 & 0 \\
\hline 3 & 1 & 0 & 0 & 0 & 0 \\
\hline 4 & 0 & 0.5 & 0 & 0 & 0 \\
\hline 5 & 0.5 & 0.5 & 0 & 0 & 0 \\
\hline 6 & 1 & 0.5 & 0 & 0 & 0 \\
\hline$\cdot$ & $\cdot$ & $\cdot$ & $\cdot$ & $\cdot$ & $\cdot$ \\
$\cdot$ & $\cdot$ & $\cdot$ & $\cdot$ & $\cdot$ & $\cdot$ \\
$\cdot$ & $\cdot$ & $\cdot$ &. &. &. \\
\hline $3^{5}-2$ & 0 & 1 & 1 & 1 & 1 \\
\hline $3^{5}-1$ & 0.5 & 1 & 1 & 1 & 1 \\
\hline $3^{5}$ & 1 & 1 & 1 & 1 & 1 \\
\hline
\end{tabular}


Table A2. Morgan Crucible Plc data

\begin{tabular}{|c|c|c|c|c|c|c|c|}
\hline year & $\mathrm{Z}$ & Directors & $\begin{array}{l}\text { Other } \\
\text { employees } \\
z_{2}\end{array}$ & $z_{C A}=z_{3}+z_{4}$ & $\begin{array}{l}\text { Average } \\
\text { wage dir } \\
p_{1}\end{array}$ & $\begin{array}{l}\text { Average } \\
\text { wage } \\
\text { employees } \\
p_{2}\end{array}$ & $\begin{array}{l}\text { Input } \\
\text { price } \\
\text { index }\end{array}$ \\
\hline 2004 & $Z^{1}$ & 8 & 12779 & 560184 & 335.51 & 24.74 & 0.9370 \\
\hline 2003 & $Z^{2}$ & 7 & 14011 & 594347 & 621.42 & 25.22 & 0.9384 \\
\hline 2002 & $Z^{3}$ & 10 & 14852 & 548202 & 134.34 & 23.38 & 0.9818 \\
\hline 2001 & $Z^{4}$ & 9 & 16084 & 534555 & 132.46 & 23.51 & 1.0032 \\
\hline 2000 & $Z^{5}$ & 9 & 16158 & 581201 & 146.22 & 24.44 & 0.9643 \\
\hline
\end{tabular}

Note: The original accounts data has been processed, by deflating all nominal variables by an appropriate monthly input price index averaged over each financial year. 
Table A3. Calculation based on prices and quantities

\begin{tabular}{|l|c|c|c|c|c|}
\hline$p^{i} Z^{i}-p^{i} Z^{j}$ & 1 & 2 & 3 & 4 & 5 \\
\hline 1 & 0 & -32156.26 & -19992.14 & -28242.93 & -52481.75 \\
\hline 2 & 32307.69 & 0 & 11534.29 & 3132.07 & -21124.42 \\
\hline 3 & 18381.33 & -13037.75 & 0 & -7513.61 & -31702.11 \\
\hline 4 & 26118.21 & -5385.39 & 7598.13 & 0 & -24193.52 \\
\hline 5 & 51887.00 & 19818.44 & 32390.96 & 24227.86 & 0 \\
\hline
\end{tabular}

Note: Calculation of expenditure differences. 
Table A4. Boolean Matrix

\begin{tabular}{|l|l|l|l|l|l|}
\hline$m_{i j}=1$ if $P^{i} Z^{i}-P^{i} Z^{j}$ & 1 & 2 & 3 & 4 & 5 \\
\hline 1 & 1 & 0 & 0 & 0 & 0 \\
\hline 2 & 1 & 1 & 1 & 1 & 0 \\
\hline 3 & 1 & 0 & 1 & 0 & 0 \\
\hline 4 & 1 & 0 & 1 & 1 & 0 \\
\hline 5 & 1 & 1 & 1 & 1 & 1 \\
\hline
\end{tabular}

Note: $m_{i j}=1$ if $P^{i} Z^{i}$ - $P^{i} Z^{j}$, that is if $Z^{i}(D R) Z^{j}$. If the ijth element of table A1.2 is positive record the value unity for $m_{i j}$ otherwise zero 


\title{
A non-parametric revealed preference test of optimal intra-firm resource allocation
}

\author{
Jonathan S. Seaton \\ Business School, \\ Loughborough University, \\ Loughborough, \\ Leicestershire LE11 3TU, \\ $U K$
}

Tel: +44 (0)1509 228838

Email: J.S.Seaton@Lboro.ac.uk

13 June, 2007

\begin{abstract}
The collective rationality hypothesis initiated by Chiappori (1988) and applied by Seaton $(1997,2001)$ for a two-person household is used to distinguish the organizational behaviour of firms. Firms produce satisfaction to groups as traditional managerial and early behavioural theories of the firm of Williamson, Baumol and Marris suggest, as well as more modern principle-agent models. Under certain conditions intra firm bargaining leads to a Pareto optimal outcome. What makes this work an important contribution is that it identifies a set of non-vacuous testable restrictions to empirically detect if firm level data satisfy Pareto optimal behaviour for the main decision makers in the organization.
\end{abstract}




\section{Introduction}

In this paper the relationship between a two-person/group organisation is introduced using traditional game theoretic models. Secondly, a set of non-vacuous conditions for the organisational choices to be compatible with any bargaining/cooperative solution (Nash (1950, 1951), Kalai-Smorodinsky (1975), Rubinstein (1982)), is determined. That data may disagree with these restrictions will imply that the firm is internally managed non-cooperatively or inefficiently relative to the objectives set by the players. The methodology is derived directly from the theoretical work of Chiappori (1988a) and empirical implementation by Seaton $(1997,2001)$. The technique has advantages over popular methods of measuring firm level efficiency which implicitly assume that firm level agents share an identical objective function.

Emphasis is made in the literature for firm behaviour to be consistent with the pursuit of pure profit maximization, see Romer (2006), revenue maximization or cost minimization, Varian (1982), when in reality firms may pursue combinations of these plus other objectives, agency, personal or even social. Our procedure does not make any of these specific assumptions except that the objective function for the firm should be concave and increasing (a production function for example, but could also represent a utility award to managers/directors or workers, see Varian (1999), p 130) and that the function can be considered as the outcome of a bargaining procedure. This is encouraging as in this sense it allows a wider class of firm level efficiency than alternative methods. Another important contribution is that it can take into account the transitivity property of players' preferences, which allows analysis of inconsistency with both the strong axiom of revealed preference (SARP) and the 
general axiom of revealed preference (GARP), which is a highly intractable problem for most data sets, see Varian (2006) and Famulari (1995).

In the following section the revealed preference problem of aggregation that lies at the heart of the issue (see Varian (1983) p. 107 and Varian (1984) pp 589-590) will be identified within a general discussion, providing a link, see Chiappori (1988b), to game theoretic solutions put forward by Nash and others. The model is formalised in Section III and restrictions are derived that data should obey for consistency with Pareto efficient behaviour. In Section IV the empirical methodology is presented with a number of examples using firm level data. The paper is concluded in Section V.

\section{Modelling Intra-firm Resource Allocation}

\section{Firm level objectives}

What are the objectives of the firm? Does the firm act as a unit aiming for maximal profits with known costs and production function? Do managers/directors pursue their own goals given some pressure from shareholders and employees? This topic has not only concerned the pure economics, organisational behaviour and the managerial economics literature but is also a popular topic for undergraduate economics

principles. As an illustration of this topicality Romer (2006) found that in the National Football League there is a departure from behaviour that would maximize the chance of winning and thus suggests other factors must be creeping in to objective functions such as complexity (agency issues) or information (use of experience rather than objective analysis).

In reality the firm like the household is an organisation made up of decision makers, internal (workers, managers, directors) and external (shareholders and pressure groups), who all benefit from the functioning of the organisation but do not 
necessarily possess common objectives, the now familiar principle-agent model, Antle and Fellingham (1990), Fama (1980), Magee (1988)) makes this distinction.

Following the collective household labour supply literature ${ }^{1}$ the objectives of the aggregate organisation are assumed dependent on the key decision makers. They are defined to hold objectives on firm level inputs $Z=\left(z_{A}, z_{B}, z_{C}\right)$, but individual objectives are not explicitly specified, neither do we need to identify who the individuals or groups are, though in many cases this should be obvious from the nature of an investigation, in company partnerships for example. Indeed the only restriction is that the individuals' $(i=A, B)$ objective functions $Y_{i}\left(z_{A}, z_{B}, z_{C}\right)$, are concave and increasing in $z_{A}, z_{B}, z_{C}$.

Difference of opinion between players is inherent in this organisation and the model does not moralise on the crude efficiency of the inputs to a specific measurable output, as it is often very hard to correctly distinguish the output from the firm i.e. as quality of product, gains in social welfare of the community. It is, however, necessary for us to address the form of player interaction in a very general manner. This does not imply a schizophrenic production function, but rather the complex interplay of group or individual objectives on the final aims of the firm. In essence a welfare function is discussed which is additively separable for each player's objectives.

\section{Disaggregated models of intra-firm choice and rationality}

To set the scene, three forms of behaviour for an organization $R$, are reviewed, differentiated by the form of their decision-making process and control over funding by two individuals or groups $A$ and $B$. The first scenario introduces basic ideas of

\footnotetext{
${ }^{1}$ See for example Leuthold (1968), Manser and Brown (1980), McElroy and Horney (1981), Lundberg (1988), Bourguinon and Chiappori (1992), Famulari (1995), Fortin and Lacroix (1997), Browning and Chiappori (1998), Vermeulen (2002).
} 
revealed preference whilst the second indicates the problem of aggregation. Our third and final case examines two-player behaviour for the organisation and highlights the problem of organisational efficiency given individual/group objectives.

At the outset the objectives of the organisation suggested may appear vague, indeed this is one of our key assumptions, however, this methodology can be constructed for the pure profit maximization objective. The following examples can be taken to represent the problems met in upstream-downstream negotiations between two profit centres for example ${ }^{2}$. Our main point in the final example is that individual rationality on the part of the profit centres might overcome collective rationality in the sense that their behaviour might not maximize the profit for the organisation as a whole, though it might optimise their individual profits given the behaviour of their rival.

\section{Common funding, common objectives}

The central concept of revealed preference is fairly straightforward (see Varian (1999, 2006)). Consider Figure 1, a firm, $A$, with only two inputs $z_{1}$ and $z_{2}$, makes a choice of input mix $A_{l}$, from the set of input mixes, on or below the current expenditure constraint $E_{1}$, like bundle $A_{3}$. Now consider a change in input prices, $z_{1}$ becomes more expensive and $z_{2}$ cheaper. Faced by a new a new expenditure constraint $E_{2}$ the firm chooses $A_{2}$, which appears to be an entirely rational choice. However if $A$ had chosen bundle $A_{3}$ rather than $A_{2}$ then it would not be a consistent choice as the firm had already revealed a preference for $A_{1}$ over $A_{3}$.

\footnotetext{
${ }^{2}$ I am grateful to an anonymous referee for this example, though all errors and omissions remain my own responsibility.
} 
Individual funding, individual objectives

Let us expand the discussion to two managers $i=A, B$, now in different branches who are allowed by the organisation $(R)$ to control their branch resources.

In Figure $1 E_{l}$ represents the initial expenditure possibilities for each of the two agents. Players $A$ and $B$ choose affordable input bundles at points $A_{l}$ and $B_{1}$ respectively. The sum of these two inputs is represented on the total expenditure constraint $T E_{l}$ at point $R_{l}$. Given the price change we saw in the previous case for player $A$, the new choices of input mix for $A$ and $B$ on the constraint $E_{2}$, are $A_{2}$ and $B_{2}$ which total to $R_{2}$ on the new total expenditure constraint, $T E_{2}$, facing the organisation. Player $A$ 's choices are consistent as before and likewise for player $B$. However, looking at the overall organisational choices, these look completely irrational as $R_{l}$ was initially chosen in preference to $R_{2}$ when both were available, but upon price change, $R_{2}$ was chosen in preference to $R_{1}$ again when both were available. Thus a Neoclassical single objective function analysis of $R$ would suggest inconsistency with rational behaviour. Given the objectives of the individuals in the firms, they have made entirely consistent decisions based on their different preferences, clearly a wider set of possibilities should be allowed for the firm for aggregation of differing individual or group choices.

[Figure 1 about here]

Common funding, individual objectives. 
Our analysis now moves on to show that even with a common pool of expenditure the bargaining solution yields a richer variation of behaviour than that based on a Neoclassical common objective function.

[Figure 2 about here]

Quadrant (I) of Figure 2 is a familiar derivation of the Cournot game solution (C). The figure plots the dictatorship or bliss points, $\left(D_{A}, D_{B}\right)$ for players $A$ and $B$ respectively where one player has controlling choice of resource allocation of three inputs $r_{A}, r_{B}, r_{C}$. Note only two inputs need be plotted $\left(r_{A}, r_{B}\right)$ as the third is determined by the level of finance and the expenditure on the other two inputs. The isoquants representing the decreasing levels of $Y$ (these can be conceived as profit, or sales isoquants) created for each individual, fan outwards from these bliss points, for $A, Y_{A 1}, Y_{A 2}, Y_{A C}, Y_{A 3}$, and for $\mathrm{B}, Y_{B 1}, Y_{B 2}, Y_{B C}, Y_{B 3}$. Reaction functions are drawn where the isoquant of one player is tangential to choices made for $z$ by the other. The Cournot-Nash equilibrium occurs where the two reaction curves cross. The level of $Y$ for the Cournot outcome is inferior to the bargaining outcome, which might occur anywhere along the line $a b$, where player isoquants are tangential to each other, indicating that joint production of $Y$ is maximized in the Pareto sense.

We can derive a similar diagram but measured in terms of the output vectors $Y_{A}, Y_{B}$ rather than inputs $z_{A}, z_{B}$. The transformation is performed through curves in quadrants (II) and (III) for $A$ and $B$ respectively. In quadrant (II) the level of $Y$ is determined from the contract curve and plotted against $z_{A}$ input. By definition the highest value of $Y$ possible is $Y_{A D}$ at point $D_{A}$ compared to the low value for player $A$ when point $D_{B}$, player $B$ 's bliss point, is reached from input pair $z_{A D B}, z_{B D B}$. Player $A$ would have to input $z_{A C}$ of $z$ along the contract curve, at point $b$, to generate the same 
level of output $Y_{A C}$ at the Cournot equilibrium (as the same isoquant $Y_{A D}$ passes through both points). The same mapping of $z$ against $Y_{A B}$ is given in quadrant (III).

If we map the results from quadrants (II) and (III) to (IV) then another familiar diagram is produced. This shows the maximal output for both players as well as the Pareto inefficient Cournot-Nash equilibrium, $C$. Points $a b$ represent the bargaining set in the sense that they signify gains to both players from cooperation and hence a motivation for optimal behaviour. The Pareto optimal solution to the bargaining outcome might come from the Nash's $(1950,1953)$ axiomatic approach (see Chiappori (1988b)) with an objective function form of $Y^{N}=\left(Y_{A}-Y_{C A}\right)\left(Y_{B^{-}} Y_{C B}\right)$, the Kalai-Smorodinsky (1975) geometrical solution or a version of the Rubinstein (1982) non-cooperative bargaining model.

The model lends itself to a useful interpretation of transaction costs. In general a collective rationality solution, that is, where the partners bargain, discuss and institute a form of sharing contract should emerge from this organisational game. If it does then the solution should emerge between a and $b$ on the contract curve (quadrant (I))/Pareto frontier (quadrant (IV)) as these points represent Pareto improvements over the Cournot solution C. On the other hand they can just do their best given what the other player might do, a non-cooperative Nash solution and many possibilities exist for the type of Nash equilibrium achieved. This would provide an inefficient solution. The choice of cooperation versus non-cooperation is the realm of the prisoners' dilemma solution where individual rationality dominates collective rationality. Noncooperative models differ from the bargaining framework in the sense that they are sub-optimal in terms of the distribution of resources between partners. Authors have increasingly been frustrated by the lack of explanation of why individuals may take up non-cooperation (strike behaviour for example, Manzini (1998))), indeed there seems 
no reason why a non-cooperative solution should exist at all given that both players lose out. The prisoners' dilemma provides a partial answer to this question, see Ostrom (2000) for a discussion of collective action, whereas the transactions cost literature probably gives us a better understanding of it (Seaton (2001)). Individuals cannot necessarily police each other due to high information asymmetry/costs and set appropriate contracts, that is, high transaction costs to bargaining may lead to a breakdown to non-cooperative behaviour.

[Table 1 about here]

It is worth reflecting on the implications of this model. As an example, two partners run an organization, $R$, and must determine the ideal level of each input. If they shared a common objective function, for example maximize output given a certain level of expenditure, it would not matter how they behaved, with full information and common aims they would still reach the same input and output decisions, the Neoclassical Pareto optimal firm, see first row of Table 1. The picture changes dramatically if the partners hold different preferences over firms' input levels and goals, see Table 1 row two. If one partner decides all, we have a Neoclassical firm result, though depending on which partner holds the position input and output choices will be different. If however democracy prevails and some form of bargaining arrangement occurs, then again we have a Pareto optimal sharing rule. Finally noncooperation of some type would yield Pareto inefficiency. Thus by allowing a simple difference of opinion in the firm many potential models of behaviour emerge. In the next section we show that revealed preference analysis allows us to test for this. 


\section{Revealed Preference Tests of Intra-firm Rationality}

\section{Methodology}

The following material is based on the revealed preference literature notably the work of Samuelson (1938a, 1938b), Houthakker (1950), Koo (1963, 1965, 1971), Dobell (1965), Afriat (1967, 1973), Uebe (1972), Diewert (1973), and Varian (1982, 1983, 1984, 2006), Chiappori (1988a, 1988b) and Seaton (1997, 2001).

The primary argument of this paper is that there is some disagreement between the players $A$ and $B$ on the actual form of the objective $Y$, this is very likely in the case for technological products where each player may hold specialist information, one may be the technical expert whilst the other may be the dynamic entrepreneurial driving force behind the product, in marketing for example. In this sense neither partner initially agrees on the optimal input mix. Thus two alternative forms for $Y$ are suggested; the first known as the Neoclassical or uniform where $Y$ is identical between individuals, $Y_{A}=Y_{B}=Y_{R}$, and represents a standard overall objective function for the organisation and the second form or individualistic where $Y$ is different between individuals, $Y_{A} \neq Y_{B}$, and some form of bargaining outcome could be achieved.

The individualistic form can be designed to capture altruistic effects, that player $A$ takes into account the consumption of the other player, a special case is the egoistic objective function is $Y_{i}\left(z_{i}, z_{C i}\right), i=A, B$. Different model forms can be suggested depending on the assumptions regarding the level of altruism, egoism on the part of the players as well as the jointness in benefit of the inputs, see Table 2 below. In Chiappori (1988a), the favoured forms were (III) versus (IV). Here the third input $z_{C}$ can be separately consumed, whereas in (I) there is no individual 
consumption. In the case of the household this may be a more relevant scenario, however for the firm either (I) versus (II) or (V) versus (VI) might be equally plausible. In (I) and (II) $A$ and $B$ consume equal quantities of the input, a public input, which seems sensible if satisfaction is based upon some output measure. The latter case, where there is joint use of inputs, might also be relevant, especially if we talk about two separate plants, which purchase inputs separately (data might be available here in certain well defined studies). However, the latter cases (V) versus (VI) may be far too general to provide sufficient restrictions on behaviour, so for this analysis we restrict our cases mainly to (I) versus (II) and use (III) versus (IV) for comparison to the initial work done by Chiappori (1988a) and Seaton (1997, 2001).

[Table 2 - about here]

For completeness we will define and compare two forms of behaviour, Organisational Neoclassical Rationality (ONR) and Organisational Collective Rationality (OCR).

\section{Organisational Neoclassical Rationality}

Our representation of the Neoclassical model assumes that the aim of the Organisation, $R$, is to optimize $Y$ which is determined purely by both players choice of business inputs $z_{A}, z_{B}, z_{C}=z_{C A}+z_{C B}$ which are jointly bought and funded from retained earnings or loans $F=F_{A}+F_{B}$. We use model (III) from the Table 2. Let

$Y=Y(Z)$, where $Z=\left(z_{A}, z_{B}, z_{C A}, z_{C B}\right)=\left(z_{1}, z_{2}, z_{3}, z_{4}\right), z_{3}=z_{4}=0.5 z_{C}$, with price vector $P=\left(w_{A}, w_{B}, 1,1\right)=\left(p_{1}, p_{2}, p_{3}, p_{4}\right)$. 
In the empirical manifestation of the model we define the main inputs as directors $\left(z_{A}\right)$ and employees $\left(z_{B}\right)$, where both enjoy some share of the input $\left(z_{C}\right)$ as before. Although hours of work is an obvious candidate, both inputs, $z_{A}, z_{B}$, could also represent the number of a particular employee type i.e. director, non-executive director, part-time or full time worker etc. This opens up a potential path of research into organizational governance issues (see Weir (1997), Leech and Manjon (2003)). It is envisaged that $z_{C}$ could represent some form of joint input for example capital, buildings, R\&D or energy inputs. The organisation's optimisation decision involves maximization of,

$Y_{R}\left(z_{A}, z_{B}, z_{C A}, z_{C B}\right)$ s.t. $F-w_{A} z_{A}-w_{B} z_{B}-z_{C} \geq 0$,

where the price of $z_{C}$ is taken as numeraire. Our only restriction on the form of $Y_{R}$ is that it be concave, differentiable and increasing. Note we have kept the model simple for convenience and practicality as both quantities and prices are not so easily recovered from standard data. In this form standard consumer revealed preference tests can be used to determine the consistency of choices with ONR.

[Table 3 about here]

In what follows we introduce three axioms of revealed preference for our two models, for convenience these six results are also summarised in Table 3. Consider a set $G(Z)$ of $n$ input bundles $Z^{1}, Z^{2}, Z^{3}, \ldots, Z^{n}$ where $Z^{k}=\left(z^{k}{ }_{1}, z^{k}{ }_{2}, z^{k}{ }_{3}, z^{k}{ }_{4}\right)$ from observed behaviour. Koo (1971) and Varian (1982) define $D R$ to mean directly revealed preferred where 
$Z^{1}(D R) Z^{2}$ if $P^{l} Z^{1} \geq P^{l} Z^{2}$

As an aid to illustration and computation of preference behaviour it is useful to introduce two concepts, digraphs and Boolean matrices. As $D R$ is a binary relationship, Koo (1971) showed that for a finite group $G(Z)$ of observed input bundles and prices a Boolean matrix could be constructed to yield a summary of the agents preference structure. From these define the $i j^{\text {th }}$ element of $M$, an $n$ by $n$ Boolean matrix as

$m_{i j}=1$ if $P^{i} Z^{i} \geq P^{i} Z^{j}$, that is if $Z^{i}(D R) Z^{j}$.

The matrix $M$ can be summarized by the use of directed graphs or digraphs. That is, for the square $(n \times n)$ Boolean matrix $M$, the digraph, $D(M)$, consists of points or vertices $V_{1}, V_{2}, \ldots, V_{n}$ and lines or edges $V_{i} V_{j}$ which exist if $m_{i j}=1$ but not if $m_{i j}=0$ in $M$.

Our question is whether this data appear to satisfy consistency of choice as a single organisation. Here we introduce a number of key axioms, from Varian (1982), the Weak Axiom of Revealed Preference (WARP) is defined in the following way, if $Z^{i}$ is directly preferred to $Z^{j}$ then bundle $j$ cannot be preferred to bundle $i$, or

$O N R W A R P=\left\{\right.$ If $Z^{i}(D R) Z^{j}$ then not $Z^{j}(D R) Z^{i}$ for $\left.Z^{i} \neq Z^{j}\right\}$

This relation is also known as an acyclic strict order relation. It is worth looking at a violation of WARP in the following four input bundle example 


$$
M=\left[\begin{array}{llll}
0 & 1 & 0 & 0 \\
1 & 0 & 0 & 0 \\
0 & 0 & 0 & 0 \\
0 & 0 & 0 & 0
\end{array}\right] \quad V_{4}
$$

Note the cycle from $V_{1}$ to $V_{2}$ and back to $V_{l}$, the digraph is not Acyclic and is a clear violation of WARP.

The next example possesses a cycle, but is not a violation of WARP. Here we need a stronger argument to capture this apparent inconsistency in choice.

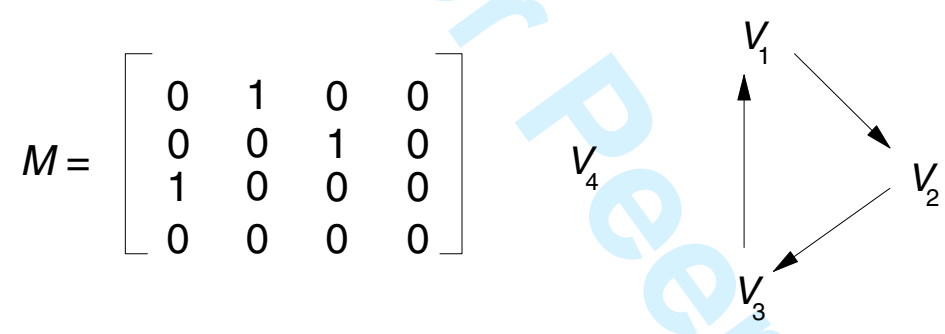

For this reason a second axiom called the Strong Axiom of Revealed Preference was suggested, and defined as,

ONRSARP $=\left\{\right.$ If $Z^{i}(R) Z^{j}$ and $Z^{i} \neq Z^{j}$ implies not $\left.Z^{j}(R) Z^{i}\right\}$

Note that the revealed preferred relation $(R)$ is the transitive closure of the relation $(D R)$, and can be written as,

$Z^{i}(R) Z^{j}$ : If $Z^{i}(D R) Z^{k}, Z^{k}(D R) Z^{l}, Z^{l}(D R) Z^{m}, Z^{m}(D R) Z^{j}$.

In this sense the data above are inconsistent with SARP because it is not acyclic, the cycle exists from $V_{1}, V_{2}$ to $V_{3}$ and back to $V_{l}$. 
However, another case with for example $Z^{1}(D R) Z^{2}$ and $Z^{3}(D R) Z^{1}$ shows the usefulness of preference revelation. Consider the Boolean matrix and digraph below, where, again WARP is satisfied.

$\mathrm{M}=\left[\begin{array}{lll}0 & 1 & 0 \\ 0 & 0 & 0 \\ 1 & 0 & 0\end{array}\right] \quad \mathrm{V}_{3}$

But through transitivity $Z^{3}(D R) Z^{1}, Z^{1}(D R) Z^{2}$ implies that $Z^{3}(R) Z^{2}$ represented in the new Boolean matrix $M^{*}$ with a star and in the digraph (11) as the dotted arrow and is consistent with SARP.

$\mathrm{M}^{*}=\left[\begin{array}{lll}0 & 1 & 0 \\ 0 & 0 & 0 \\ 1 & 1^{*} & 0\end{array}\right] \quad \mathrm{V}_{3}^{\prime \prime}$

This discussion can now be completed by looking at a final axiom, which is less restrictive than SARP but does take into account transitivity, the Generalized Axiom of Revealed Preference can be written as,

ONRGARP $=\left\{\right.$ If $Z^{i}(R) Z^{j}$ implies not $Z^{j}(S D R) Z^{i}$, for $\left.Z^{i} \neq Z^{j}\right\}$,

where Strictly Directly Revealed Preferred $(S D R)$, is represented by $Z^{i}(S D R) Z^{j}$ : If $P^{i} Z^{i}$ $>P^{i} Z^{j}$, consequently if $m_{i j}{ }^{*}=1$ and $P^{j} Z^{j}>P^{j} Z^{i}$ then GARP is violated.

Organisational collective rationality (OCR) 
Following Varian (1984, p 590 Theorem 11), Chiappori(1988a) and Seaton(1997, 2001) and arguing that some form of bargaining compromise (sharing rule, see Chiappori (1988a)) is reached then partners optimise,

$Y=a_{1} Y_{1}(Z)+a_{2} Y_{2}(Z)$

over quantities $Z=\left(z_{A}, z_{B}, z_{C A}, z_{C B}\right)=\left(z_{1}, z_{2}, z_{3}, z_{4}\right)$, subject to prices $P=\left(w_{1}, w_{2}, 1,1\right)$ $=\left(p_{1}, p_{2}, p_{3}, p_{4}\right)$ where $a_{1}, a_{2} \geq 0, a_{1}+a_{2}=1, a_{i}=a_{i}\left(w_{1}, w_{2}, F_{1}, F_{2}, X_{1}, X_{2}\right), i=1,2$ and $\left(X_{1}, X_{2}\right)$ represents characteristics of the players.

OCRWARP, OCRGARP and OCRSARP can be written in a similar way to their ONR analogues excepting that they must take into account two restrictions, each based upon the personal prices for each group, as well as taking into account the jointness, if any, assumed in the inputs. It is worth noting that ONR is a special case of OCR when either $a_{1}=a_{2}=0.5$ or one $a_{i}$ is zero. As $p_{q}$ represents the price of input $z_{q}$ where $q=1,2,3,4$, following Chiappori (1988) and Seaton (1997) if we observe a $\operatorname{mix} Z^{j}, j=1,2, \ldots, N$ is chosen then $Z^{j} P^{j} \geq Z P^{j}$ and $Z^{j}$ is revealed preferred to all other affordable Z. The general firm level bargaining optimisation problem can be expressed as,

$\Lambda=a_{1}^{j} Y_{1}(Z)+a_{2}^{j} Y_{2}(Z)+\lambda^{j}\left(Z^{j} P^{j}-Z P^{j}\right), \quad j=1,2, \ldots, N$.

Differentiating with respect to individual $i$ 's desired input of $q$ we get

$a_{1}^{j} Y_{1 i q}+a_{2}^{j} Y_{2 i q}=\lambda^{j} p_{q}^{j}, \quad j=1,2, \ldots, N$ 
dividing this expression through by $\lambda^{j}$ and noting that the new expression simply stated uses the additive separability of the individual utility functions to split the value of price to individual level shadow/personal prices, the expression can be rewritten as

$\theta^{j}{ }_{i q} p_{q}^{j}+\left(1-\theta^{j}{ }_{i q}\right) p_{q}^{j}=p_{q}^{j}, \quad j=1,2, \ldots, N$, and $\theta^{j}{ }_{i q} \geq 0$

We require for each individual that each set of personal prices and quantities satisfy individual rationality. So for collective rationality to be true here, both individual rationalities must be satisfied given the nature of the choices made and values of the shadow prices $\left(\theta^{j}{ }_{i q} p_{q}^{j},\left(1-\theta^{j}{ }_{i q}\right) p_{q}^{j}\right)$, though aggregate prices and input quantities may not agree with ONR.

Tests for the rationality of choices for one individual (ONR) given prices and bundles chosen are straightforward to do using revealed preference techniques. As we typically possess data regarding quantities of inputs, then the form of $Z$ is typically known. Similarly we also normally possess information as to the value of input prices. However we do not know the individual valuation $(\theta)$ put on these inputs by the bargainers, although we do know their bounds $(p \geq p \theta \geq 0)$. Further we cannot perceive the individual levels of inputs selected except of course for example the total number of employees or directors.

For the moment let us proceed as if we do know these values. For each observation $j, k=1 \ldots N$ we can construct two Boolean matrices representing the preference choices for $i=A, B$ respectively depending on the personal prices they possess. That is 
$M_{i}^{j k}=1$ if $\rho_{i}^{j}\left(Z^{j}-Z^{k}\right) \geq 0$ otherwise $M_{i}^{j k}=0$

where $\rho_{A}^{j}=\left(\theta^{j}{ }_{A 1} p_{1}^{j}, \theta^{j}{ }_{A 2} p_{2}{ }^{j}, \theta^{j}{ }_{A 3} p_{3}^{j}, \theta^{j}{ }_{A 4} p_{4}{ }^{j}\right)=\left(\theta^{j}{ }_{A 1} w_{A}{ }^{j}, \theta^{j}{ }_{A} w_{B}^{j}, \theta^{j}{ }_{A 3}, \theta^{j}{ }_{A 4}\right)$,

$$
\begin{aligned}
& \rho_{B}^{j_{B}}=\left(\left(1-\theta^{j}{ }_{A 1}\right) p_{1}^{j},\left(1-\theta^{j}{ }_{A 2}\right) p_{2}{ }^{j},\left(1-\theta^{j}{ }_{A 3}\right) p_{3}{ }^{j},\left(1-\theta^{j}{ }_{A 4}\right) p_{4}{ }^{j}\right) \\
& =\left(\left(1-\theta^{j}{ }_{A 1}\right) w_{A}^{j},\left(1-\theta^{j}{ }_{A 2}\right) w_{B}^{j},\left(1-\theta^{j}{ }_{A 3}\right),\left(1-\theta^{j}{ }_{A 4}\right)\right) .
\end{aligned}
$$

Noting that $Z=\left(z_{A}, z_{B}, z_{C A}, z_{C B}\right)=\left(z_{1}, z_{2}, z_{3}, z_{4}\right)$ then as the data on individual quantities of $z_{C}$ may only exist in aggregated form we introduce another fifth parameter to indicate that the division is unknown, thus,

$z_{C}^{j}=\theta^{j}{ }_{A 5} z_{C A},+\left(1-\theta^{j}{ }_{A 5}\right) z_{C B}$

The final result of our comparison with personal prices is the two Boolean matrices $M_{A}^{j k}$ and $M_{B}^{j k}$ where $j, k=1 \ldots N$. The OCRWARP test to determine (for each parameter search) whether for all $k$ and $j$ that for individuals/groups $A, B$, is

If $M_{A}^{j k}=1$ implies not $M_{A}^{k j}=1$ and $j \neq k$

and If $M_{B}^{j k}=1$ implies not $M_{B}^{k j}=1$ and $j \neq k$

in which case the data does not conflict with that particular realization of the bargaining model. A failure to find any parameter values that satisfy individual rationality for each matrix would imply some deviation from the bargaining model i.e. non-cooperative behaviour. Note this is a weak axiom of revealed preference (WARP) realisation of the problem, SARP and GARP can also be introduced by derivation of the $M^{*}$ Boolean matrices $\left(M_{A}^{* j k}\right.$ and $\left.M_{B}^{* j k}\right)$ as before for the Neoclassical case, see propositions in Table 3. 


\title{
IV. Empirical Methodology, Examples and Results
}

\section{Empirical Methodology for OCR}

\begin{abstract}
Although the ONR implementation is straightforward, OCR is much more problematic as the parameters $\theta_{A 1}^{j}, \theta^{j}{ }_{A 2}, \theta^{j}{ }_{A 3}, \theta^{j}{ }_{A 4}, \theta^{j}{ }_{A 5}, j=1,2, \ldots N$ are unknown, trial values must be inserted to minimize the number of CR inconsistencies. For a few observations ( 3 say) this is a trivial exercise, but for large $N, 5 N$ parameters must be searched and the problem becomes highly intractable. For example searching 5 parameters over 7 trial values for $\mathrm{N}$ observations or $7^{5 \mathrm{~N}}$ trials (for 10 observations $7^{50} \approx 1.798 \times 10^{42}$, thus if each trial takes one billionth of a second to calculate it would still take centuries to check through each trial). So some simplification was needed especially for samples sizes of $\mathrm{N}=50$ or more.
\end{abstract}

A two stage method was adopted to take account of similarities and differences of parameters across observations, remember that the Neoclassical model assumes all parameters are fixed at 0.5 for all observations, so we are allowing a high degree of flexibility in the search.

Stage 1. Capture parameter homogeneity across observations.

A grid search fixing $\theta^{j}{ }_{A 1}, \theta^{j}{ }_{A 2}, \theta^{j}{ }_{A 3}, \theta^{j}{ }_{A 4}, \theta^{j}{ }_{A 5}$ for all $\mathrm{j}$ to $\theta_{A 1}, \theta_{A 2}, \theta_{A 3}, \theta_{A 4}, \theta_{A 5}$ and varying these between 0 and 1 inclusive. For example if we try out values $0,0.5$ and 1 , 
[Table 4 about here]

there is a symmetry here, trial 1 is equivalent to trial $3^{5}$ (we need only do half the trials). If $\omega+1$ values chosen, $0,1 / \omega, 2 / \omega, \ldots, \omega / \omega$, then $\left((\omega+1)^{5}-1\right) / 2$ combinations or if $\omega=7$ then $(16807-1) / 2=8403$ trials need to be made, however for most data $\omega=2$ appeared adequate. We checked that no Boolean matrix collapsed to a null.

Stage 2. To capture observational heterogeneity.

A grid search for each observation at a time $\theta^{j}{ }_{A 1}, \theta^{j}{ }_{A 2}, \theta^{j}{ }_{A 3}, \theta^{j}{ }_{A 4}, \theta^{j}{ }_{A 5}, j=1,2, \ldots N$ was carried out for the same $\omega+1$ values. For $\mathrm{N}$ observations this means $\mathrm{N}(\omega+1)^{5}$ combinations and a total of $(\mathrm{N}+1)(\omega+1)^{5}$ combinations for both stages. Stage 2 was repeated $\sigma$ number of times. Thus $(\sigma \mathrm{N}+1)(\omega+1)^{5}$ trials altogether.

\section{Examples}

In all four examples below firms were selected where they reported sales, depreciation, employment, number of directors, director remuneration, total remuneration and operating profit. The measure of total expenditure is total sales minus operating profit plus depreciation and the cost of each input is calculated in a simplified manner. The cost of a director is simply the average directors' remuneration, whilst employees' wages are calculated in a similar way.

\section{Example One: Morgan Crucible PIc}


[Table 5 about here]

Table 5 presents data from Morgan Crucible Plc over the years 2000 to 2004. All variables have been deflated by an appropriate input price index. Let the group $G(Z)$ be restricted to 5 input bundles, $G(Z)=\left[Z^{1}, Z^{2}, Z^{3}, Z^{4}, Z^{5}\right]$ the matrix of expenditure differences $\left(P^{i} Z^{i}-P^{i} Z^{j}\right)$ is calculated and presented in Table 6.

[Table 6 about here]

[Table 7 about here]

Noting the positive and negative values we can then construct the Boolean matrix in Table 7, which can be suitably represented by the digraph, Figure 3. It is easy to verify that there are no cycles in this graph, nor any patterns that lend themselves to new preference revelation through transitivity.

[Figure 3 about here]

The Morgan Crucible data appear entirely consistent with all axioms, ONRWARP, ONRGARP, ONRSARP and therefore OCRWARP, OCRGARP and OCRSARP. As this data is consistent with that of the Neoclassical organisation, how do we interpret these results? This means we cannot rule out that the objectives of the organization are so firmly held in stone and agreed by decision makers that bargaining is not a necessary complexity to modelling the outcome or that a dictatorship point like $D_{A}$ in Figure 2 exists. Nor can we rule out the possibility that the firm behaves as a bargaining institution. 


\section{Example Two: Multinational corporations industry wide.}

A heterogeneous sample of very large firms were derived in a sample of 92 quoted companies from the Datastream (Worldscope) database in different industries with sales in the US, Europe and the UK over a period of at least 14 years, sampled in the year 2003. There were no restrictions placed on industry, employees etc. Indeed heterogeneity was the desired goal. In this sense it is expected that a high degree of inconsistency should be found with ONR. The number of inconsistencies with ONRWARP and ONRSARP are 36 and 48 respectively, both less than $1 \%$ of possible inconsistencies, which does not seem particularly high. However, testing for OCR (see Table 8) also finds inconsistency with the Pure input form, both SARP and WARP.

[Table 8 about here]

This indicates complicating factors emerge in this group of firms, which we discuss later. However the data are consistent with the Joint version of all OCR axioms and the Pure realisation of OCRGARP. This could point to the possibility that individuals are unable to have much impact on firm objectives in large organisations.

\section{Example Three : The computer industry}

In total the FAME database holds 2228 companies in the 4-digit SIC category 3002, the manufacture computers and other information processing equipment, this includes 2058 identifiable public and private limited companies of which 22 are public limited. After selecting on our desired variables a sample of 107 firms remained. We find as 
before, see Table 8, that there is inconsistency with ONR. In fact 180 for ONRWARP (just 1\%) and 1044 for ONRSARP (5\%) which is a great deal higher than we expected from the previous example as these firms belong to the same industry with the same accounting years. Just as with Example Two we find inconsistency with Pure OCR but consistency with Joint OCR.

\section{Example Four: The computer industry, sub-sampled by size}

For a more in depth analysis of the data presented in example three the sample of 107 companies is split into sub-samples of 30 then 50 firms by size of firm (sales). Thus the first sample of 30 firms would consist of the smallest 30 firms. The second subsample would contain the same firms except the smallest would be replaced by the $31^{\text {st }}$ smallest. This sampling progresses until the final sub-sample which would contain the top 30 largest firms.

Sub-samples of size 30 and 50 violate all ONR axioms as with examples two and three. Interestingly the number of inconsistencies displayed in Figures 4 and 6, by size of firm in each sub-sample, indicate a rise in inconsistency until a peak for medium sized firms, falling off for large firms. This is represented by a U-shaped trough for the 'Goodness of fit' measure used (see note to Table 8).

[Figure 4 about here]

The tests of inconsistency with OCR (Pure version) were very surprising. Here, see Figures 5 and 7, small to medium firms appear to have behaved consistently with the OCR hypothesis of bargaining behaviour. However, the larger firms did not. On the plus side the data are consistent in all cases with the joint third input model and the Pure OCRGARP axiom. 
[Figure 5 about here]

The results together appear to indicate that intra-firm resource allocation is determined by a successful bargaining form between the key decision makers in small to medium firms. Increasing further the size of firm tends to bring in complicating features that are not assumed in the bargaining model. There are many possible factors. First, bargaining may be failing to some form of non-cooperation (increasing transactions costs i.e. policing and information failure) as discussed in previous sections. Second, a much wider set of individuals/groups might be involved in the bargaining situation (shareholders, directors, managers, other employees (trade unions, see Mumford (1996)).

[Figure 6 about here]

[Figure 7 about here]

\section{Concluding Comments}

The aims of this paper were twofold. First to show that the firm could be viewed as an organization where decision makers can hold differences of opinion and, secondly, to produce a workable test of organisational form. Given this interpretation of the firm, 
revealed preference methods for examining the implications of aggregated behaviour were presented. Four examples with three different sample types indicate the applicability of these methods and provide some explanation of apparent inconsistency with traditional Neoclassical techniques (ONR).

The key conclusion from the brief application of this methodology is that smaller firms (at least in the computing industry) appear to possess cooperative decision making behaviour though larger firms may not. The failure of some data to fulfil the restrictions imposed by the OCR model is in some sense absolute, though none failed OCRGARP in any examples. The cause of failure may be the existence of more than two decision making groups, aggregation of inputs and also whether there are competitive labour markets, as well as the comparability of firms in each sample.

The main contribution of this work is that we now have a methodology that allows us to filter data for potential governance implications on input demand as Seaton (2001) shows for the household organisation. In this sense we can analyse whether hierarchy/governance may be failing to allow decision makers to realize their goals. Although this paper has been directed at determining inconsistency with the underlying model, further work should also be targeted at the implications for restrictions on input demand functions as this is a fairly straightforward application of Chiappori's (1988a) contribution. 


\section{References}

Afriat, S. N. (1967) The construction of utility functions from expenditure data, International Economic Review, 8, 67-77.

Afriat, S. N. (1973) On a system of inequalities in demand analysis: an extension of the classical method, International Economic Review, 14, 460-72.

Antle, R. and Fellingham, J. (1990) Resource rationing and organizational slack in a two-period model, Journal of Accounting Research, 28, 3-24.

Bourguinon, F. and Chiappori, P. A. (1992) Collective models of household behaviour, European Economic Review, 36, 355-64.

Browning, M. and Chiappori, P. A. (1998) Efficient intra-household allocations: a general characterization and empirical tests, Econometrica, 66, 1241-78.

Chiappori, P. A. (1988a) Rational household labor supply, Econometrica, 56, 63-89.

Chiappori, P.A. (1988b) Nash-bargained households decisions: a comment, International Economic Review, 29, 791-96.

Dasgupta, I. (2005) Consistent firm choice and the theory of supply, Economic Theory, 26, 167-75.

Diewert, W.E. (1973) Afriat and revealed preference theory, The Review of Economic Studies, 40, 419-25.

Dobell, A. R. (1965) A comment on A.Y. Koo's: an empirical test of revealed preference theory, Econometrica, 33, 451-55.

Fama, E. (1980) Agency problems and the theory of the firm, The Journal of Political Economy, 88, 288-307.

Famulari (1995), A household-based, non-parametric test of demand theory, The Review of Economics and Statistics, 77, 372-82.

Fortin, B. and Lacroix, G. (1997) A test of the unitary and collective models of household labour supply, The Economic Journal, 107, 933-55.

Green, H. A. J. (1976) Consumer Theory Revised Edition, The MacMillan Press Ltd, London and Basingstoke.

Houthakker (1950), Revealed Preference and the utility function, Economica New Series, 17, 159-74.

Kalai, E. and Smorodinsky, M. (1975) Other solutions to Nash's bargaining problem, Econometrica, 43, 513-8. 
Koo, A. Y. C. (1963) An empirical test of revealed preference theory, Econometrica, 31, 646-64.

Koo, A. Y. C. (1965) Reply, Econometrica, 33, 456-8.

Koo, A. Y. C. (1971) Revealed preference - a structural analysis, Econometrica, 39, 89-97.

Leech, D. and Manjon, M.C. (2003) Corporate governance and game theoretic analysis of shareholder power: the case of Spain, Applied Economics, 35, 847858.

Leibenstein, H. (1966) Allocative efficiency and x-efficiency, The American Economic Review, 56, 392-415.

Leuthold, J.E. (1968) An empirical study of formula income transfers and the work decision of the poor, Journal of Human Resources, 3, 312-23.

Magee, R. P. (1988) Variable cost allocation in a principle/agent setting, The Accounting Review, 63, 42-54.

Manser, M. and Brown, M.(1980) Marriage and household decision making: a bargaining analysis, International Economic Review, 21, 31-44.

Manzini, P. (1998) Game theoretic models of wage bargaining, Journal of Economic Surveys, 12, 1-41.

McElroy, M.B. and Horney, M.J. (1981) Nash - bargained household decisions: toward a generalization of the theory of demand, International Economic Review, 22, 333-49.

Mumford, K. (1996) Strikes and profits: considering an asymmetric information model, Applied Economics Letters, 3, 545-548.

Nash, J. (1950) The Bargaining Problem, Econometrica, 18, 155-62.

Nash, J. (1951) Two-person cooperative games, Econometrica, 21, 128-40.

Ostrom, E. (2000) Collective action and the evolution of social norms, Journal of Economic Perspectives, 14, 137-58.

Romer, D. (2006) Do firms maximize? Evidence from professional football, Journal of Political Economy, 114, 340-65.

Rubinstein, A. (1982) Perfect equilibrium in a bargaining model, Econometrica, 50, 97-110.

Samuelson (1938a), A note on the pure theory of consumer's behaviour, Economica New series, 5, 61-71. 
Samuelson (1938b), A note on the pure theory of consumer's behaviour- an addendum, Economica New series, 5, 353-4.

Seaton, J. S. (1997) Neoclassical and collective rationality in household labour supply, Applied Economics Letters, 4, 529-33.

Seaton, J. S. (2001) Bargaining versus non-cooperation; transactions costs within marriage, Applied Economics Letters, 8, 37-41.

Uebe, G. (1972) A note on Anthony Y.C.Koo, "Revealed preference - A structural Analaysis", Econometrica, 40, p. 771.

Varian, H. R. (1982) The nonparametric approach to demand analysis, Econometrica, 50, 945-73.

Varian, H. R. (1983) Non-parametric tests of consumer behaviour, Review of Economic Studies, 50, 99-110.

Varian, H. R. (1984) The Nonparametric Approach to Production Analysis, Econometrica, 52, 579-98.

Varian, H. R. (1999) Intermediate Microeconomics: A Modern Approach, $5^{\text {th }}$ Edition, W.W. Noton \& Company, New York, ISBN 0-393-97370.

Varian, H. R. (2006) Revealed preference, http://www.sims.berkeley.edu/ hal/Papers/2005/revpref.pdf

Vermeulen, F. (2002) Collective household models: principles and main results, Journal of Economic Surveys, 16, 533-64.

Weir, C. (1997) Corporate governance, performance and take-overs: an empirical analysis of UK mergers, Applied Economics, 29, 1465-1475. 
Figure 1. The Aggregation Problem for A and B (Adapted from Green (1976), p. 144)

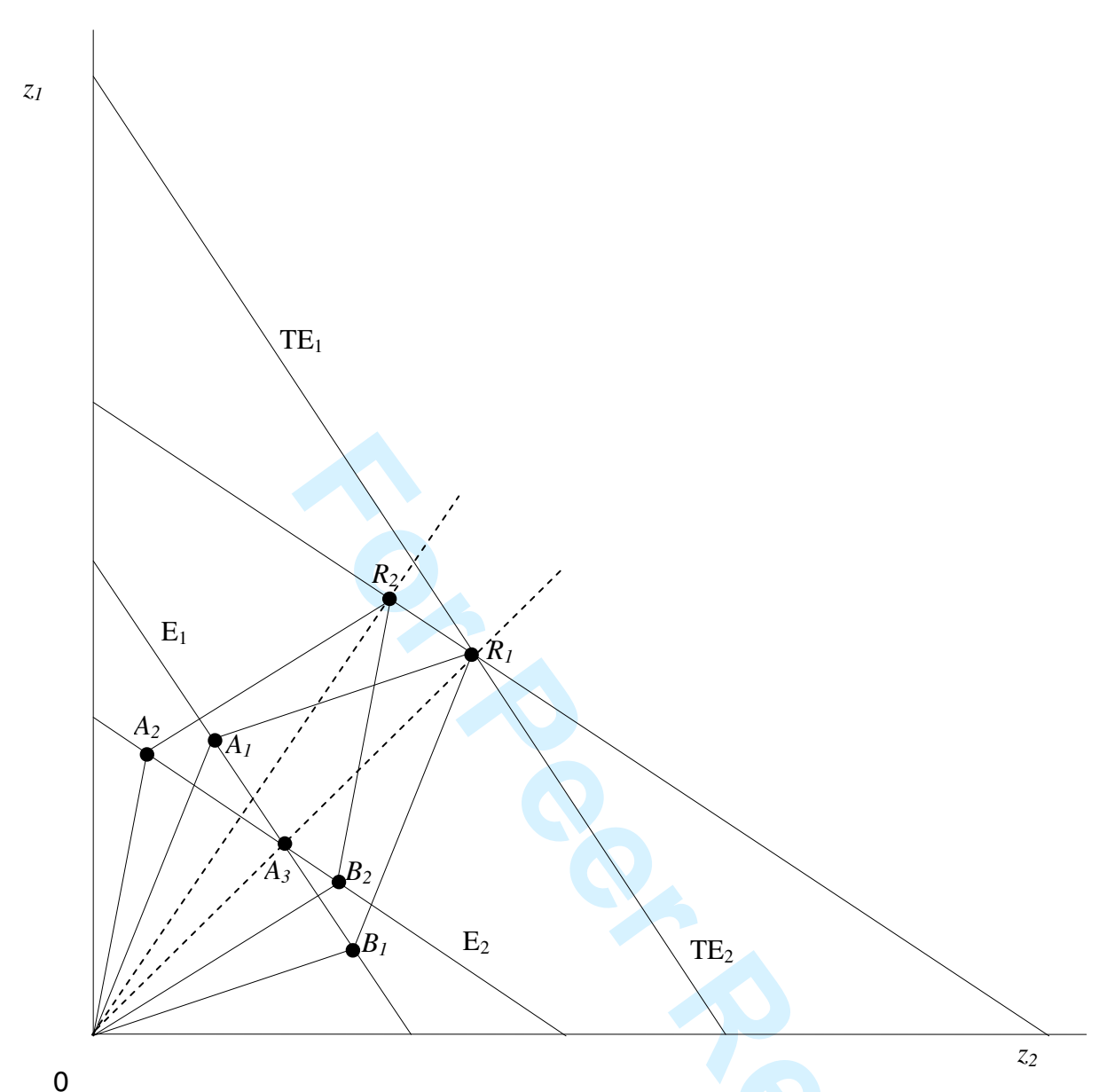

Editorial Office, Dept of Economics, Warwick University, Coventry CV4 7AL, UK 
Figure 2. Comparison of models

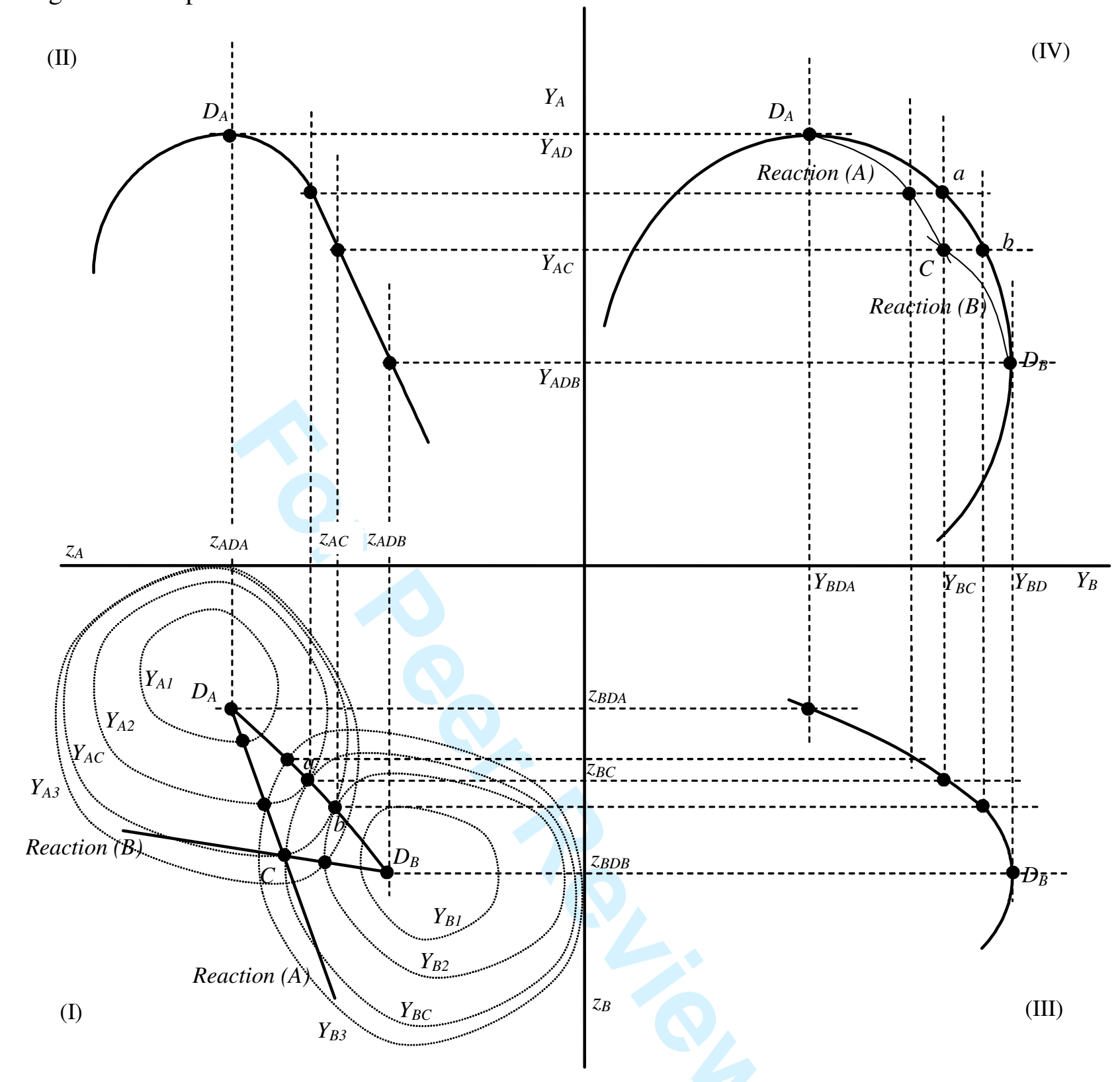


Figure 3. Digraph of Morgan Crucible's preferences

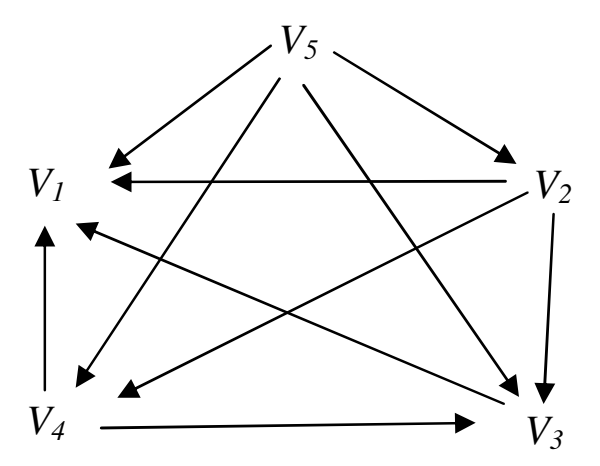


Figure 4. ONR Goodness of fit for Example Four

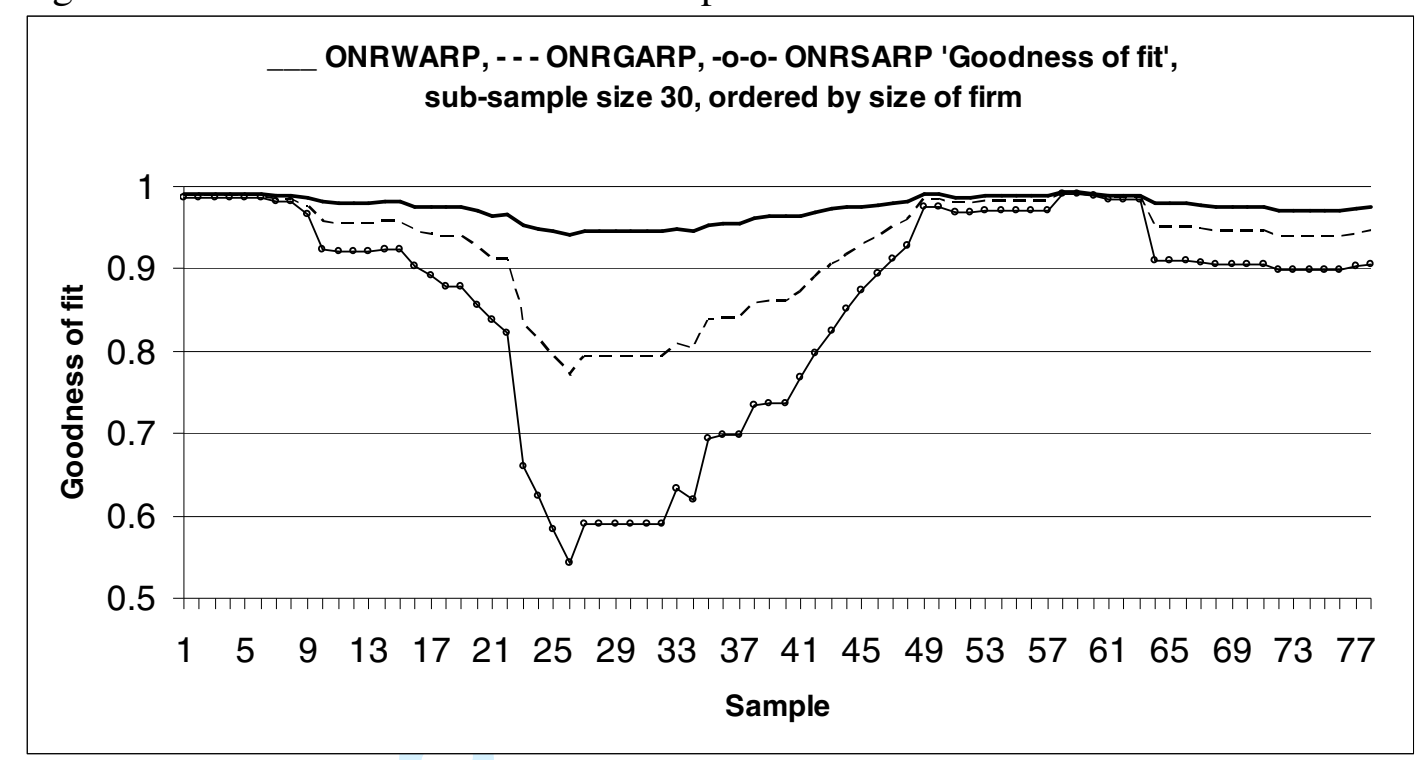


Figure 5. OCR Goodness of fit for Example Four, note GARP =1 throughout

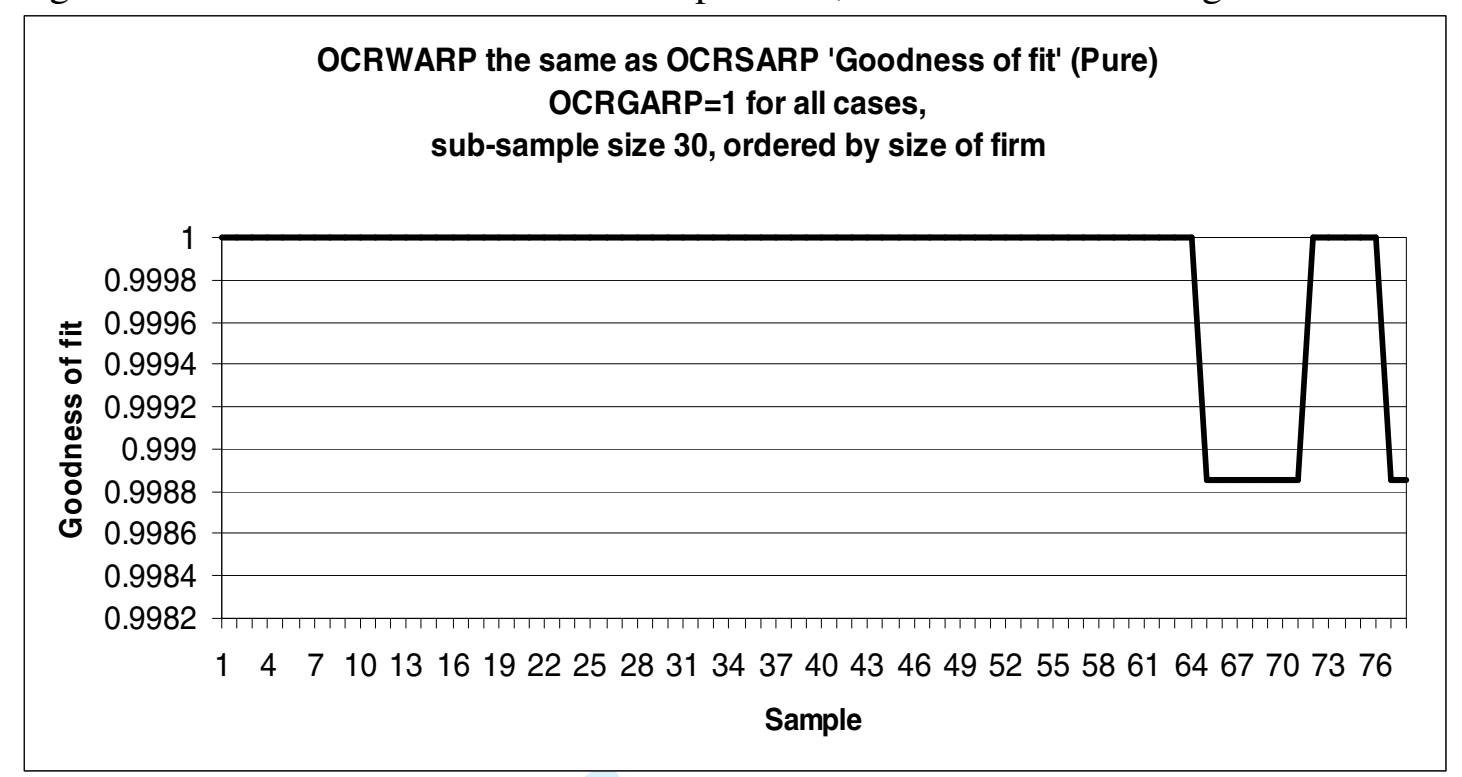


Figure 6. ONR Goodness of fit for Example Four, Sub sample size=50

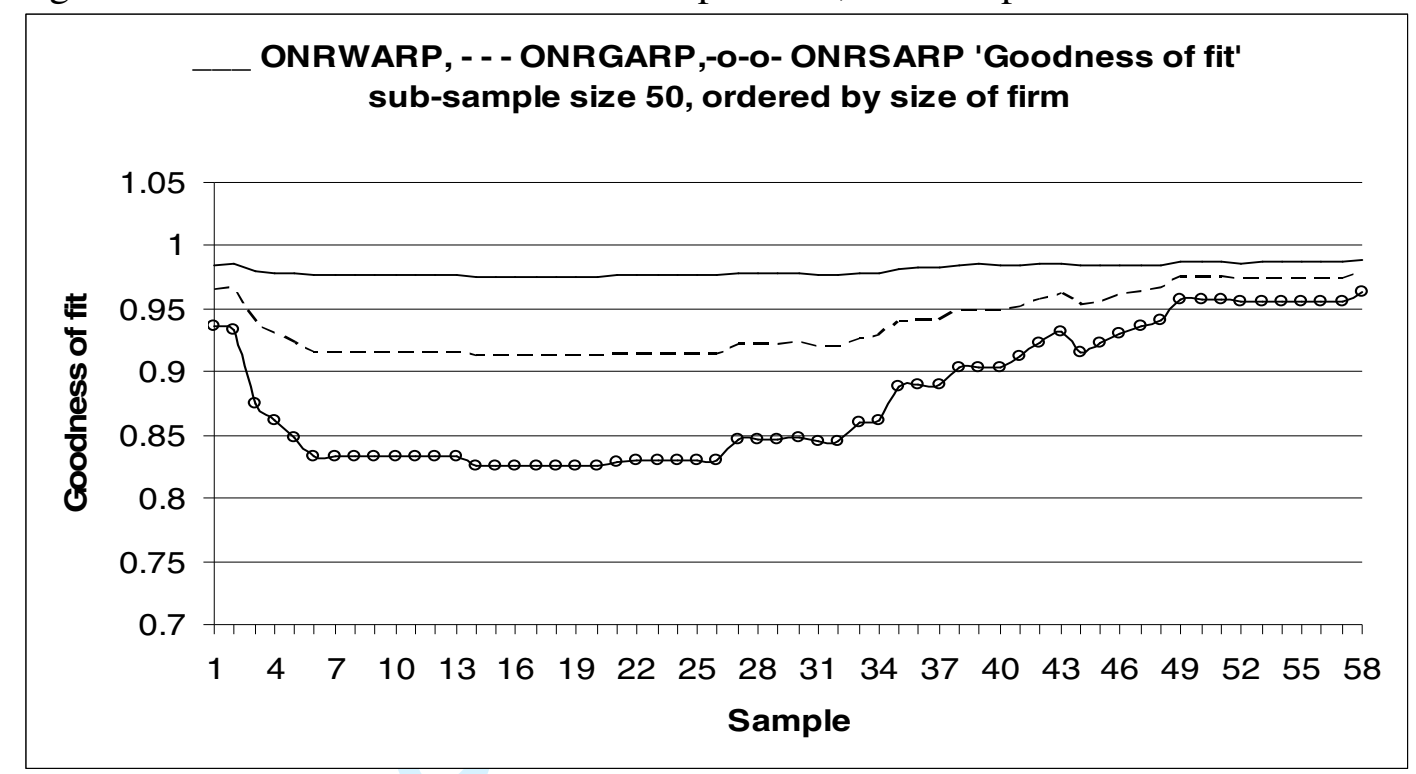


Figure 7. OCR Goodness of fit for Example Four, note GARP $=1$ throughout, subsample size $=50$.

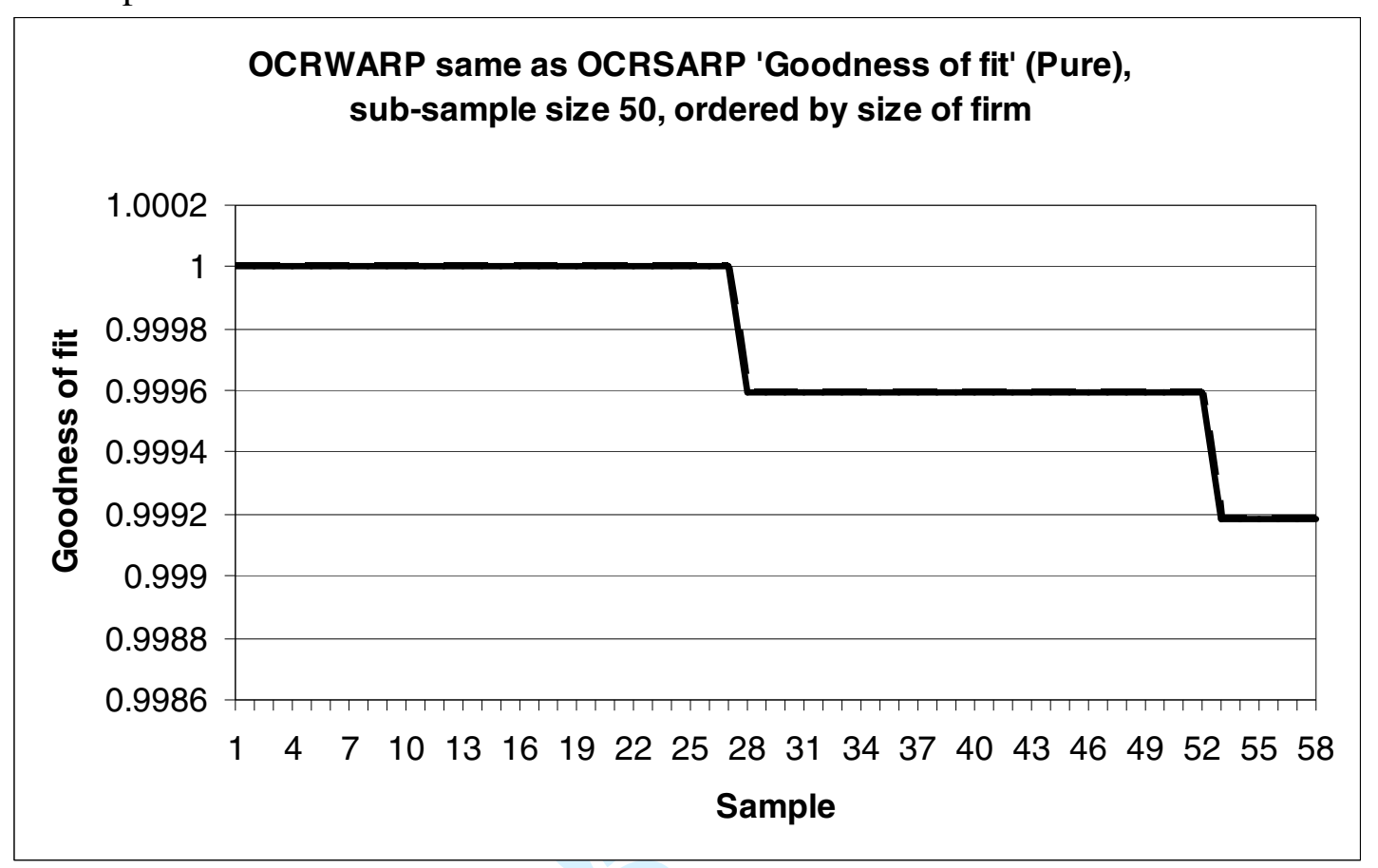


Table 1. Governance and difference of opinion

\begin{tabular}{|c|c|c|c|}
\hline $\begin{array}{l}\text { Objectives } \\
\text { (preferences) }\end{array}$ & $\begin{array}{l}\text { Governance } \\
\text { and institutional } \\
\text { relationships }\end{array}$ & & \\
\hline & $\begin{array}{c}\text { Autocracy } \\
\text { Dictatorship }\end{array}$ & $\begin{array}{l}\text { Democracy } \\
\text { Bargaining } \\
\end{array}$ & $\begin{array}{c}\text { Anarchic } \\
\text { Non-cooperative }\end{array}$ \\
\hline Homogeneous & $\begin{array}{c}\text { Neoclassical } \\
\text { Pareto Optimal } \\
\text { (One solution, } Y^{R} \text { ) }\end{array}$ & $\begin{array}{c}\text { Neoclassical } \\
\text { Pareto Optimal } \\
\left.\text { (One solution, } Y^{R}\right)\end{array}$ & $\begin{array}{c}\text { Neoclassical } \\
\text { Pareto Optimal } \\
\left(\text { One solution } Y^{R}\right)\end{array}$ \\
\hline Heterogeneous & $\begin{array}{c}\text { Neoclassical } \\
\text { Pareto Optimal } \\
\text { (Two solutions } \\
\left.D_{B}, D_{A}\right)\end{array}$ & $\begin{array}{l}\text { Pareto Optimal } \\
\text { (Complex, many } \\
\text { solutions } \\
\text { depending on } \\
\text { bargaining power } \\
\text { or Nash } Y^{N} \text { ) }\end{array}$ & $\begin{array}{l}\text { Pareto Inefficient } \\
\text { (Complex, } \\
\text { many solutions, like } \\
\text { Cournot C) }\end{array}$ \\
\hline
\end{tabular}


Table 2. Alternative objective functions for decision makers in the firm

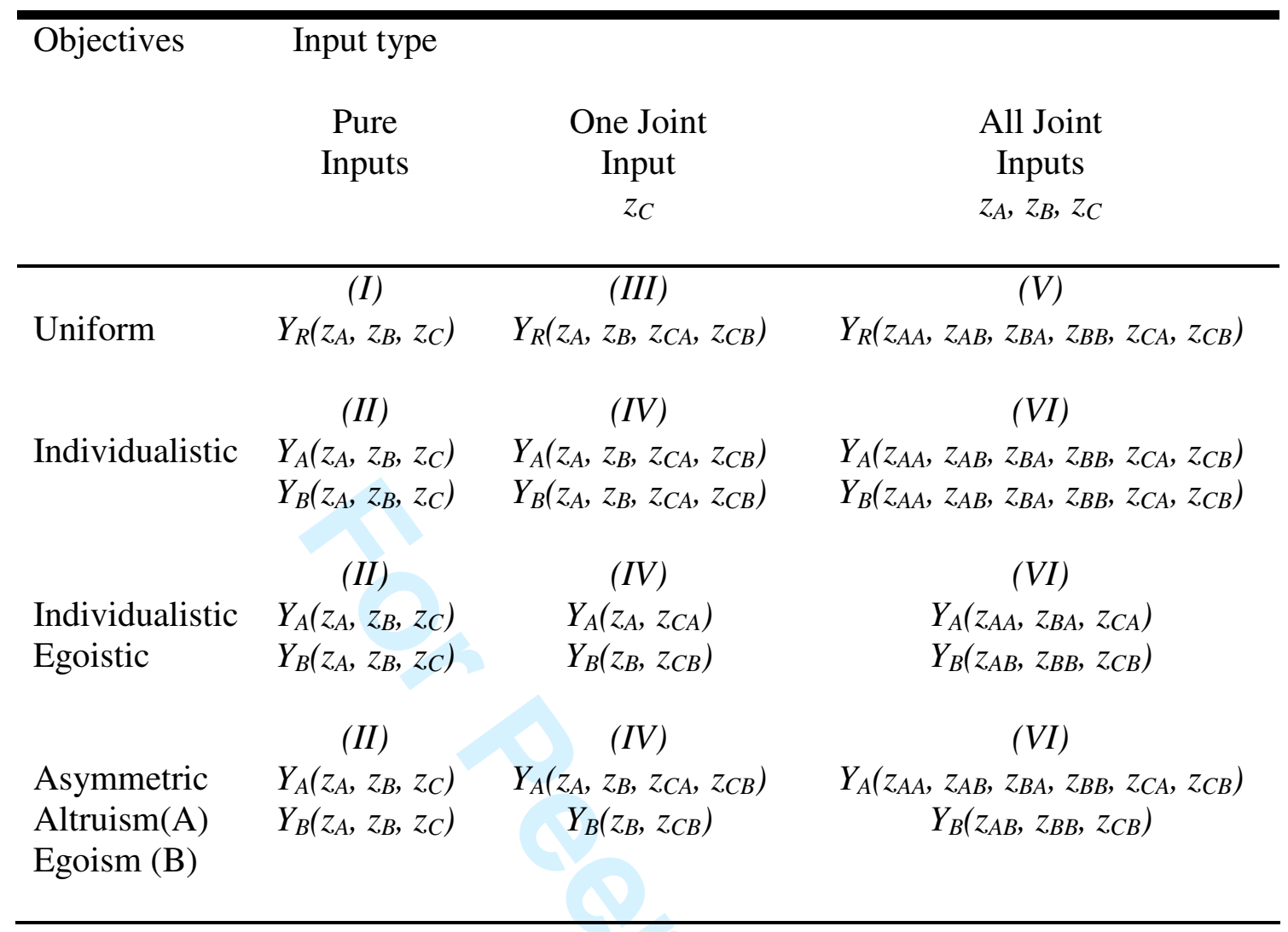


Table 3. Definitions, Propositions, Axioms, References in text

\begin{tabular}{|c|c|c|c|}
\hline Mnem & Name & Proposition/Axiom & Reference \\
\hline ONR & $\begin{array}{l}\text { Organisational } \\
\text { Neoclassical } \\
\text { Rationality }\end{array}$ & $\begin{array}{l}\text { Identical personal prices }\left(\rho_{A}^{j}=\rho_{B}=0.5 P^{j}\right) \\
\text { for individuals/groups A and B }\end{array}$ & Section III \\
\hline OCR & $\begin{array}{l}\text { Organisational } \\
\text { Collective Rationality }\end{array}$ & $\begin{array}{l}\text { Personal prices differ }\left(\rho_{A}^{j} \neq \rho_{B}^{j}\right) \text { but } \\
\rho_{A}+\rho_{B}^{j_{B}}=P^{j}\end{array}$ & Section III \\
\hline ONRWARP & $\begin{array}{l}\text { ONR Weak Axiom of } \\
\text { Revealed Preference }\end{array}$ & If $Z^{i}(D R) Z^{j}$ then not $Z^{j}(D R) Z^{i}$ for $Z^{i} \neq Z^{j}$ & Equation 5 \\
\hline ONRSARP & $\begin{array}{l}\text { ONR Strong Axiom of } \\
\text { Revealed Preference }\end{array}$ & If $Z^{i}(R) Z^{j}$ and $Z^{i} \neq Z^{j}$ implies not $Z^{j}(R) Z^{i}$ & Equation 8 \\
\hline ONRGARP & $\begin{array}{l}\text { ONR General Axiom of } \\
\text { Revealed Preference }\end{array}$ & If $Z^{i}(R) Z^{j}$ implies not $Z^{j}(S D R) Z^{i}$ & $\begin{array}{l}\text { Equation } \\
\quad 12\end{array}$ \\
\hline OCRWARP & $\begin{array}{l}\text { OCR Weak Axiom of } \\
\text { Revealed Preference }\end{array}$ & $\begin{array}{l}\text { a) If } M_{A}^{j k}=1 \text { implies not } M_{A}^{k j}=1 \text { and } j \neq k \\
\text { and }\end{array}$ & $\begin{array}{l}\text { Equation } \\
\quad 19\end{array}$ \\
\hline OCRSARP & $\begin{array}{l}\text { OCR Strong Axiom of } \\
\text { Revealed Preference }\end{array}$ & $\begin{array}{l}\text { b) If } M^{j k}{ }_{B}=1 \text { implies not } M_{B}^{k j}=1 \text { and } j \neq k \\
\text { a) If } M^{* j k}{ }_{A}=1 \text { implies not } M^{* k j}=1 \text { and } j \neq k \\
\text { and } \\
\text { b) If } M^{* j k}{ }_{B}=1 \text { implies not } M^{* k j}=1 \text { and } j \neq k\end{array}$ & $\begin{array}{l}\text { Analogous } \\
\text { to Equation } \\
\quad 8\end{array}$ \\
\hline OCRGARP & $\begin{array}{l}\text { OCR General Axiom of } \\
\text { Revealed Preference }\end{array}$ & $\begin{array}{l}\text { a) If } M_{A}^{* j k}=1 \text { implies not if } \rho_{A}^{j_{A}}\left(Z_{A}^{j}-Z_{A}^{k}\right)>0 \\
=1 \text { and } j \neq k \text { and } \\
\text { b) if } M^{* j k}{ }_{B}=1 \text { implies not if } \rho_{B}\left(Z_{B}^{j}-Z_{B}^{k}\right)>0 \\
=1 \text { and } j \neq k \text {. }\end{array}$ & $\begin{array}{c}\text { Analogous } \\
\text { to Equation } \\
9\end{array}$ \\
\hline \multicolumn{4}{|c|}{$\begin{array}{l}\text { Note: For } n \text { input bundles } Z^{l}, Z^{2}, Z^{3}, \ldots, Z^{n} \text { with associated price vectors }\left(P^{l}, P^{2}, P^{3}, \ldots, P^{n}\right) \text { where } Z^{k}=\left(z^{k},{ }^{k}, z^{k} \text {, }\right. \\
\left.z^{k}, z^{k}, \ldots\right) \text { the preference relation } D R \text { (Directly Revealed Preferred) is represented by } Z^{l}(D R) Z^{2} \text { if } P^{l} Z^{l} \\
P^{l} Z^{l} \text {. The relation } R \text { is defined as the transitive closure of } D R \text {, for example } Z^{i}(R) Z^{j}: \text { If } Z^{i}(D R) Z^{k} \text {, } \\
Z^{k}(D R) Z^{l}, Z^{l}(D R) Z^{m}, Z^{m}(D R) Z^{j} \text {. SDR is the Strictly revealed preferred relation, see definition given for } \\
\text { Equation } 12 \text {. Define the } i j^{t h} \text { element of } M \text {, as an } n \text { by } n \text { Boolean matrix with } m_{i j}=1 \text { if } P^{i} Z^{i} \geq P^{i} Z^{j} \\
\left.\text { (equivalently if } Z^{i}(D R) Z^{j}\right) \text { and zero otherwise. } M^{*} \text { is identical to } M \text { except that the ijh elements are set } \\
\text { to unity where } Z^{i}(R) Z^{j} \text {. For the ONR cases } M \text { is based on prices (i.e. } P \text { ) whereas for the OCR cases two }\end{array}$} \\
\hline
\end{tabular}


Table 4. Parameter trial values

\begin{tabular}{llllll}
\hline Trial & $\theta_{A 1}$ & $\theta_{A 2}$ & $\theta_{A 3}$ & $\theta_{A 4}$ & $\theta_{A 5}$ \\
\hline 1 & 0 & 0 & 0 & 0 & 0 \\
2 & 0.5 & 0 & 0 & 0 & 0 \\
3 & 1 & 0 & 0 & 0 & 0 \\
4 & 0 & 0.5 & 0 & 0 & 0 \\
5 & 0.5 & 0.5 & 0 & 0 & 0 \\
6 & 1 & 0.5 & 0 & 0 & 0 \\
$\cdot$ & $\cdot$ & $\cdot$ & $\cdot$ & $\cdot$ & $\cdot$ \\
$\cdot$ & $\cdot$ & $\cdot$ & $\cdot$ & $\cdot$ & $\cdot$ \\
$\cdot$ &. &. &. & $\cdot$ & $\cdot$ \\
$3^{5}-2$ & 0 & 1 & 1 & 1 & 1 \\
$3^{5}-1$ & 0.5 & 1 & 1 & 1 & 1 \\
$3^{5}$ & 1 & 1 & 1 & 1 & 1 \\
\hline
\end{tabular}


Table 5. Morgan Crucible Plc data

\begin{tabular}{ccclllll}
\hline Year & $Z$ & Directors & $\begin{array}{l}\text { Other } \\
\text { employees }\end{array}$ & Expenditure & $\begin{array}{l}\text { Average } \\
\text { wage dir }\end{array}$ & $\begin{array}{l}\text { Average } \\
\text { wage } \\
\text { employees }\end{array}$ & $\begin{array}{l}\text { Input } \\
\text { price } \\
\text { index }\end{array}$ \\
\hline 2004 & $Z^{1}$ & $z_{1}$ & $z_{2}$ & $z_{C A}=z_{3}+z_{4}$ & $p_{I}$ & $p_{2}$ & \\
2003 & $Z^{2}$ & 7 & 12779 & 560184 & 335.51 & 24.74 & 0.9370 \\
2002 & $Z^{3}$ & 10 & 14011 & 594347 & 621.42 & 25.22 & 0.9384 \\
2001 & $Z^{4}$ & 9 & 14852 & 548202 & 134.34 & 23.38 & 0.9818 \\
2000 & $Z^{5}$ & 9 & 16084 & 534555 & 132.46 & 23.51 & 1.0032 \\
\hline
\end{tabular}

Note: The original accounts data has been processed, by deflating all nominal variables by an appropriate monthly input price index averaged over each financial year. 
Table 6. Calculation based on prices and quantities

\begin{tabular}{lccccc}
\hline$p^{i} Z^{i}-p^{i} Z^{j}$ & 1 & 2 & 3 & 4 & 5 \\
\hline 1 & 0 & -32156.26 & -19992.14 & -28242.93 & -52481.75 \\
2 & 32307.69 & 0 & 11534.29 & 3132.07 & -21124.42 \\
3 & 18381.33 & -13037.75 & 0 & -7513.61 & -31702.11 \\
4 & 26118.21 & -5385.39 & 7598.13 & 0 & -24193.52 \\
5 & 51887.00 & 19818.44 & 32390.96 & 24227.86 & 0 \\
\hline
\end{tabular}

Note: Calculation of expenditure differences. 
Table 7. Boolean Matrix

\begin{tabular}{llllll}
\hline$m_{i j}=1$ if $P^{i} Z^{i}-P^{i} Z^{j}$ & 1 & 2 & 3 & 4 & 5 \\
\hline 1 & 1 & 0 & 0 & 0 & 0 \\
2 & 1 & 1 & 1 & 1 & 0 \\
3 & 1 & 0 & 1 & 0 & 0 \\
4 & 1 & 0 & 1 & 1 & 0 \\
5 & 1 & 1 & 1 & 1 & 1 \\
\hline
\end{tabular}

Note: $m_{i j}=1$ if $P^{i} Z^{i}-P^{i} Z^{j}$, that is if $Z^{i}(D R) Z^{j}$. If the $\mathrm{ij}^{\text {th }}$ element of Table 6 is positive record the value unity for $m_{i j}$ otherwise zero. 
Table 8. Goodness of fit

\begin{tabular}{lccc}
\hline Goodness of fit & Example & & \\
& $\begin{array}{c}\text { Morgan } \\
\text { Crucible } \\
(N=5)\end{array}$ & Multinationals & Computing \\
Axiom & 1 & $0.9978(36)$ & $(N=107)$ \\
\hline ONRWARP & 1 & $0.9977(38)$ & $0.9921(180)$ \\
ONRGARP & 1 & $0.9971(48)$ & $0.9757(550)$ \\
ONRSARP & 1 & $0.9998(4)$ & $0.9998(4)$ \\
OCRWARP (Pure) & 1 & 1 & 1 \\
OCRGARP (Pure) & 1 & $0.9998(4)$ & $0.9998(4)$ \\
OCRSARP (Pure) & 1 & 1 & 1 \\
OCRWARP (Joint) & 1 & 1 & 1 \\
OCRGARP (Joint) & 1 & 1 & 1 \\
OCRSARP (Joint) & 1 & 1 & 1 \\
\hline
\end{tabular}

Note: These measures of goodness of fit should not be confused with those encountered in econometrics and statistics as they refer to some suggestions in the revealed preference literature. Essentially any inconsistency means failure, however authors such as Varian (2006) feel that useful information can be gleaned from investigation the inconsistencies further. For a short survey of goodness of fit measures see Varian (2006). We use the formula (TPI-TI)/TPI where TPI is the Total Possible Inconsistencies $\left(2\left(N^{2}-N\right)\right)$ from two unit matrices (both groups) and $T I$ is the Total of Inconsistencies found, Famulari (1995), Varian (2006). Thus a value of unity implies no inconsistencies, below unity means the data is inconsistent but provides a feel for how bad it is. 